\title{
Measurements and modelling of molecular iodine emissions, transport and photodestruction in the coastal region around Roscoff
}

\author{
R. J. Leigh ${ }^{1}$, S. M. Ball ${ }^{2}$, J. Whitehead ${ }^{3}$, C. Leblanc ${ }^{4}$, A. J. L. Shillings ${ }^{5}$, A. S. Mahajan ${ }^{6}$, H. Oetjen ${ }^{6}$, J. D. Lee ${ }^{7}$, \\ C. E. Jones ${ }^{7}$, J. R. Dorsey ${ }^{3}$, M. Gallagher ${ }^{3}$, R. L. Jones ${ }^{5}$, J. M. C. Plane ${ }^{6}$, P. Potin ${ }^{4}$, and G. McFiggans ${ }^{3}$ \\ ${ }^{1}$ Department of Physics and Astronomy, University of Leicester, Leicester, UK \\ ${ }^{2}$ Department of Chemistry, University of Leicester, Leicester, UK \\ ${ }^{3}$ School of Earth, Atmospheric and Environmental Sciences, University of Manchester, Manchester, UK \\ ${ }^{4}$ Station Biologique de Roscoff, UPMC-CNRS, UMR 7139, Roscoff, France \\ ${ }^{5}$ Department of Chemistry, University of Cambridge, Cambridge, UK \\ ${ }^{6}$ School of Chemistry, University of Leeds, Leeds, UK \\ ${ }^{7}$ Department of Chemistry, University of York, York, UK
}

Received: 11 September 2009 - Published in Atmos. Chem. Phys. Discuss.: 7 October 2009

Revised: 1 November 2010 - Accepted: 5 November 2010 - Published: 13 December 2010

\begin{abstract}
Iodine emissions from the dominant six macroalgal species in the coastal regions around Roscoff, France, have been modelled to support the Reactive Halogens in the Marine Boundary Layer Experiment (RHaMBLe) undertaken in September 2006. A two-dimensional model is used to explore the relationship between geographically resolved regional emissions (based on maps of seaweed beds in the area and seaweed $\mathrm{I}_{2}$ emission rates previously measured in the laboratory) and in situ point and line measurements of $\mathrm{I}_{2}$ performed respectively by a broadband cavity ringdown spectroscopy (BBCRDS) instrument sited on the shoreline and a long-path differential optical absorption spectroscopy (LP-DOAS) instrument sampling over an extended light path to an off-shore island. The modelled point and line $\mathrm{I}_{2}$ concentrations compare quantitatively with BBCRDS and LPDOAS measurements, and provide a link between emission fields and the different measurement geometries used to quantify atmospheric $\mathrm{I}_{2}$ concentrations during RHaMBLe. Total $\mathrm{I}_{2}$ emissions over the $100 \mathrm{~km}^{2}$ region around Roscoff are calculated to be $1.7 \times 10^{19}$ molecules per second during the lowest tides.
\end{abstract}

During the night, the model replicates $I_{2}$ concentrations up to 50 pptv measured along the LP-DOAS instrument's line of sight, and predicts spikes of several hundred pptv in certain conditions. Point $I_{2}$ concentrations up to $50 \mathrm{pptv}$ are also calculated at the measurement site, in broad agreement

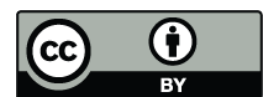

Correspondence to: R. J. Leigh (r.j.leigh@leicester.ac.uk) with the BBCRDS observations. Daytime measured concentrations of $I_{2}$ at the site correlate with modelled production and transport processes. However substantial recycling of the photodissociated $\mathrm{I}_{2}$ is required for the model to quantitatively match measured concentrations. This result corroborates previous modelling of iodine and $\mathrm{NO}_{\mathrm{x}}$ chemistry in the semi-polluted marine boundary layer which proposed a mechanism for recycling $\mathrm{I}_{2}$ via the formation, transport and subsequent reactions of the $\mathrm{IONO}_{2}$ reservoir compound.

The methodology presented in this paper provides a tool for linking spatially distinct measurements to inhomogeneous and temporally varying emission fields.

\section{Introduction}

Most techniques for measuring atmospheric composition provide a single point observation from which conclusions are then sought over a wider region or scenario. Other techniques such as long-path differential optical absorption spectroscopy (LP-DOAS) provide integrated measurements along a folded line of sight between a light source and retroreflector. The relationship between point and line data (and a campaign's wider conclusions) can be understood by a relatively simple model linking the measurements to temporally varying and spatially inhomogeneous concentrations in the region around the monitoring site. Results are presented here from a model of molecular iodine emissions during the RHaMBLe campaign hosted at the Station Biologique de Roscoff (SBR) in late summer 2006 (McFiggans et al.,

Published by Copernicus Publications on behalf of the European Geosciences Union. 
2010). This model is used to place novel measurements of $I_{2}$ from broadband cavity ring-down spectroscopy (BBCRDS) and LP-DOAS instruments into a regional context.

Coastal emissions of reactive halogen gases merit investigation owing to their linkages with perturbations of tropospheric radical chemistry, aerosol particle nucleation and possible climate impacts (von Glasow and Crutzen, 2007; McFiggans et al., 2010). In coastal regions, $I_{2}$ has been shown to be a significantly larger source of iodine atoms than iodocarbons (McFiggans et al., 2004), with elevated localised concentrations of $\mathrm{I}_{2}$ measured at Mace Head, Ireland, peaking around low tide (Saiz-Lopez and Plane, 2004; SaizLopez et al., 2006). Mahajan et al. (2009) also observed $I_{2}$ around low tides during RHaMBLe, as discussed further in this work.

\section{The model}

The present model incorporates two horizontal spatial scales and a temporal domain, with an additional vertical component included in footprint modelling calculations. The horizontal grid consists of 746 by 227 elements, each of $0.0005 \times 0.0005$ degrees extending from -4.2075 to -3.835 degrees longitude, and 48.6725 to 48.7855 degrees latitude. In the Roscoff region, this resolution corresponds to grid boxes of approximately $36.7 \mathrm{~m}$ longitudinally by $55.6 \mathrm{~m}$ latitudinally. Bathymetry and macroalgal distribution information was mapped on to this model grid. Tide and meteorological data was applied to this spatial information at 1-min resolution from 5 to 28 September 2006 during the RHaMBLe campaign.

\subsection{Seaweed speciation and site bathymetry}

The Roscoff inter-tidal zone in front of the SBR extends more than five kilometers in length and about $1 \mathrm{~km}$ in width. Mapping of the seaweed beds in the vicinity of Roscoff has been attempted in two main studies. One in the early 1970s (Braud, 1974) combined aerial photographs and in situ observations obtained from diving and field measurements. The second study in the 1990s used both field and airborne spectrometers to map the seaweed and seagrass beds near Roscoff (Bajjouk et al., 1996). The published maps from these previous studies were used to construct a dedicated map for this work which was further validated by field observations from September 2006 to September 2009. This seaweed map was then superposed with a bathymetry map of the area provided by L. Leveque from the Service Mer et Observation (Roscoff). The resulting mapped distributions of Laminaria digitata, Laminaria hyperborea, Laminaria ochroleuca, Saccharina latisima, Fucus and Ascophyllum are shown in Fig. 1. Ascophyllum and Fucus beds are inherently mixed, and are mapped together: a con-

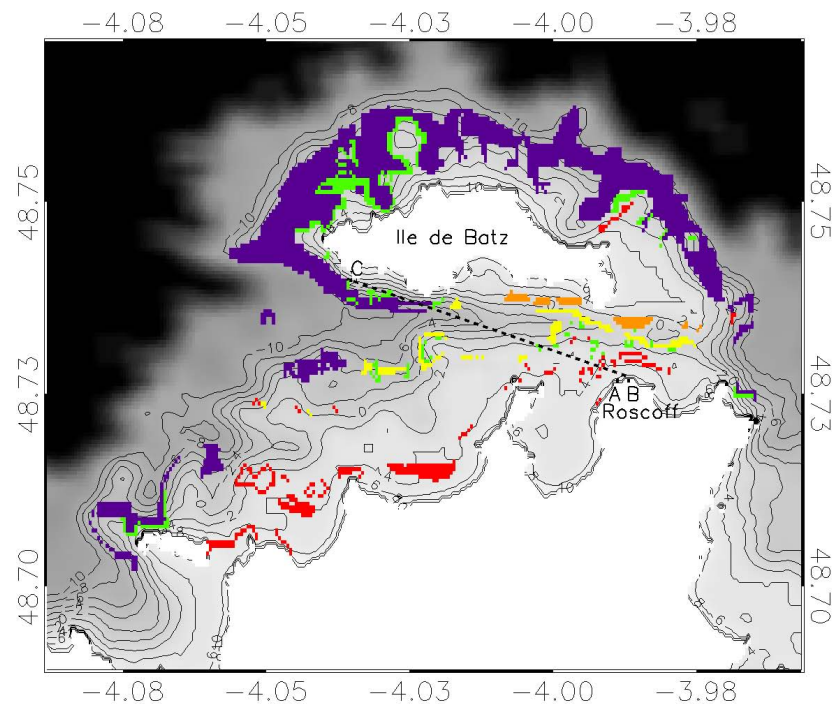

Fig. 1. Bathymetry map and algal distributions used as inputs for this modelling work. The following key locations are marked; the main measurement site (A), the LP-DOAS telescope (B) and the LP-DOAS retroreflector $(\mathbf{C})$. Seaweed species are coded as follows: L. hyperborea - purple, L. digitata - green, L. ochroleuca - orange, Saccharina latissima - yellow, Ascophyllum/Fucus - red.

stant mixing ratio of 65:35 for Ascophyllum:Fucus was used in modelling their emissions.

The vertical zonation of seaweed species is very distinct on rocky shores with each species often forming a belt at a certain elevation in the eulittoral zone (the area between the highest and the lowest tides) and also in the subtidal zone (the area extending below the zero of the marine charts). It is thought that the driving force of this zonation is a combination of biotic factors and the tolerance of the different species to abiotic factors such as temperature, light, salinity, dehydration, and mechanical forces caused by wave action (Lüning, 1990). A typical kelp bed from the Roscoff region is shown in Fig. 2.

In the North Atlantic, as exemplified in the study site in front of the SBR, the eulittoral zone in sheltered habitats is dominated both in coverage and biomass by brown algal species of the order of Fucales (fucoids), such as Fucus spp. and Ascophyllum nodosum. In addition, four species of the order Laminariales (kelps) are distributed in distinct populations forming belts. Laminaria digitata occurs in the lowest part of the eulittoral zone and in the upper subtidal zone, with Laminaria hyperborea extending from the upper subtidal zone to a limit of depth conditioned by the light penetration (about $20 \mathrm{~m}$ at Ile de Batz, Table 1). Laminaria ochroleuca appears in habitats protected from the dominant wind, either mixed with Laminaria hyperborea and Saccharina lattisima or in monospecific stands, and mainly restricted to shallow waters. 


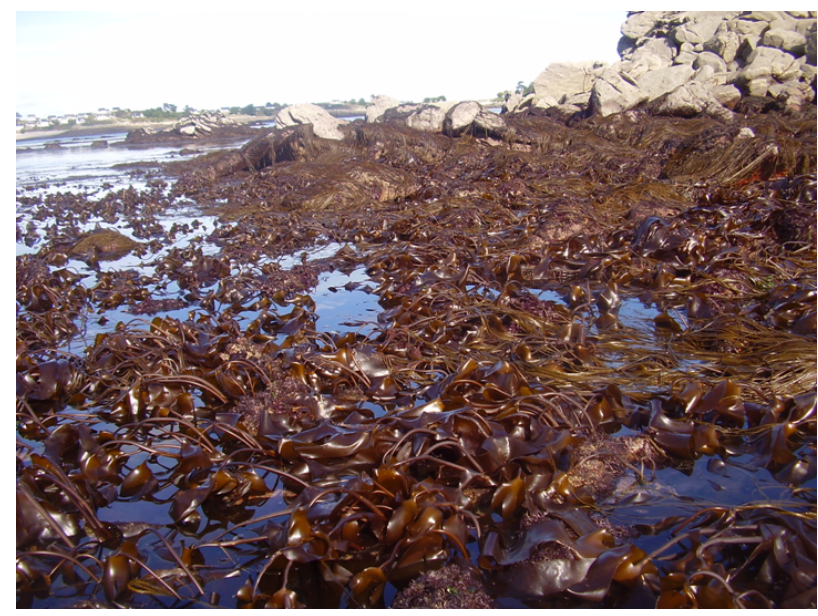

Fig. 2. The kelp bed at the Rocher du Loup, at a low tide of about $0.5 \mathrm{~m}$ dominated by L. digitata (kelp) and just above a belt of Himanthalia elongata (fucoid)

The shallow inter-tidal zone at Roscoff results in the waters closest to the shoreline being too shallow for Laminariales species. So although a large horizontal surface area of seaweed beds becomes exposed at low tide immediately in front of the SBR, this mainly consists of fucoids (see Fig. 1). The distribution of seaweed species is rather patchy in the inter-tidal zone and is mainly dominated by Fucus spp. and Ascophyllum beds, however there is also a small amount of $L$. digitata, Saccharina latissima and L. ochroleuca in the channel and tide pools between the site and the Ile de Batz island to the north. The south shore of Ile de Batz includes sheltered shallow patchy habitats with sand and gravel which surround rocky areas covered by fucoids except where exposed to strong tide currents. Laminaria (mainly hyperborea) beds extend to the north of Ile de Batz, whereas L. digitata flourishes in moderately exposed areas or at sites with strong water currents in the western part of the study site (Ile de Batz and islets west of Perharidy) and north-east from the Ile de Batz. L. digitata also occurs in rockpools up to mid-tide level and higher on wave-exposed coasts of the Ile de Batz.

The average biomass densities in Table 1 were obtained from recent studies on Ascophyllum nodosum at Roscoff (Golléty et al., 2008) and L. digitata (Gévaert et al., 2008), and from the extensive long-term survey of Laminariales populations by Ifremer (Arzel, 1998) using the average biomass of L. digitata in September over the last ten years. The average volumic mass of each species was determined experimentally by filling a one-litre volume with seaweed thalli and determining the fresh weight of 5 replicates. The depth limits of the various species at Roscoff were obtained from previous mapping studies and from the Service Mer et Observation, in agreement with published data (Lüning, 1990).

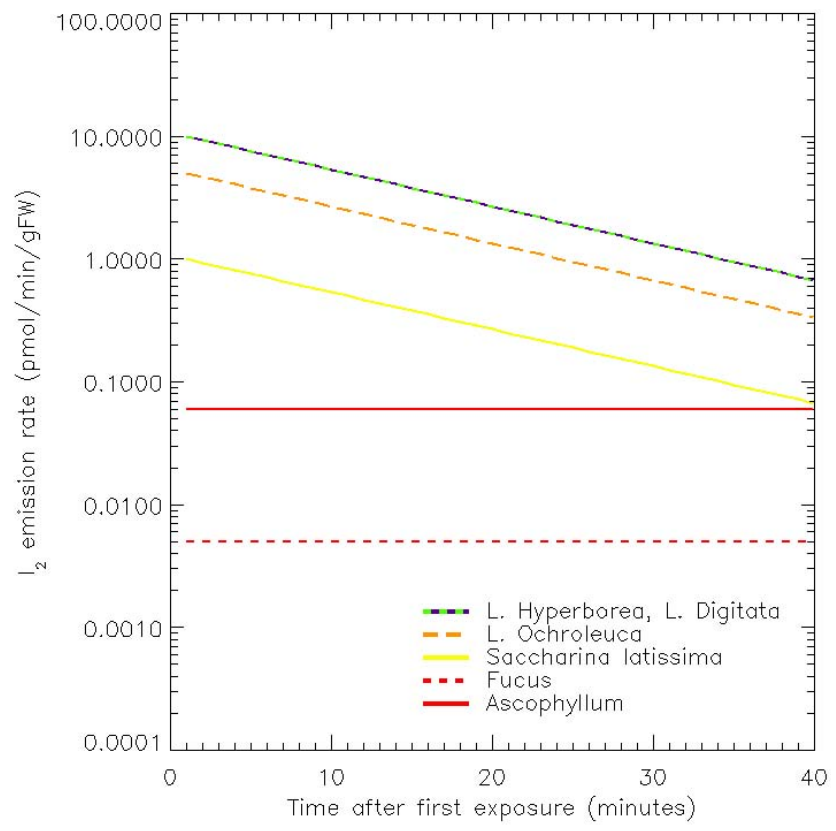

Fig. 3. Emission rates assumed for the six species of macroalgae as a function of time following exposure to the atmosphere.

\subsection{Emission rates from exposed macroalgae}

$\mathrm{I}_{2}$ emission rates for each species of macroalgae were estimated from the time since each model grid square was first exposed to air by the changing tide, and from the propensity of each seaweed species to emit. For the former, each seaweed species was given a height attribute in the model in order to account for the variable length and structure of the plants, and therefore the variable water height at which the seaweed first breaks the water surface and becomes exposed to air. These heights are shown in Table 1 and result in the $\mathrm{I}_{2}$ modelled emissions starting slightly in advance of the surrounding sea bed itself becoming exposed. Species specific $\mathrm{I}_{2}$ emission rates (in picomoles per minute per gramme fresh weight) were parameterised from the laboratory study of Ball et al. (2010). Figure 3 shows the time dependent emission rates for each seaweed species used in this work. Fucus species and Ascophyllum were assumed to emit at a constant rate when exposed to air. Emission rates of the Laminaria species were assumed to decline after first exposure to air with a common half life of $10 \mathrm{~min}$ utes. Laboratory studies have also found that $L$. digitata can sometimes resume bursts of strong $\mathrm{I}_{2}$ emission after having been exposed to air for long periods (Dixneuf et al., 2009; Ball et al., 2010): for simplicity here, emission rates for each species are assumed to become constant after $40 \mathrm{~min}$ utes of continuous exposure. Emissions from all species cease immediately once the seaweed is re-covered by the incoming tide. L. ochroleuca, for which measured emission data were not available, was assumed to emit at a rate 
intermediate between L. digitata and Saccharina latissima. These emission rates were converted into emissions per $\mathrm{m}^{2}$ sea surface area using the assumptions shown in Table 1 of mass per $\mathrm{m}^{2}$ by species. Emissions were assumed to mix into an atmosphere layer of $15 \mathrm{~cm}$ depth, providing a conversion into volume mixing ratio (VMR). This assumption produces peak VMRs immediately above the most stronglyemitting species, L. hyperborea and L. digitata, of approximately 15 ppbv (parts per billion by volume) immediately after their first exposure to air, consistent with the peak VMRs observed by Ball et al. (2010) in their laboratory study.

Actinic fluxes of solar radiation were measured using a Metcon spectral radiometer (Edwards and Monks, 2003), and were used to calculate the photolysis frequencies of a number of trace gases, including molecular iodine $\left(j \mathrm{I}_{2}\right)$ - see Fig. 4 . The model temporal resolution was matched to the meteorological dataset sampling of $1 \mathrm{~min}$, with all times within the model expressed in Universal Time. The model was applied to data from 5 to 28 September 2006.

\subsection{Footprint analysis}

Concentration footprints (as opposed to the more often used flux footprints) were calculated for a range of wind velocities and representative meteorological conditions using the analytical approximation of Schmid (1994). The model is a numerical solution to an analytical approximation of the advection-diffusion equations. The heterogeneity of the upwind surface makes it rather difficult to draw firm conclusions about the exact form of the concentration footprint, nevertheless the model is capable of providing sufficiently detailed estimates for the purposes of this study.

A surface roughness length, $z_{0}$, of $0.03 \mathrm{~m}$ was used where the fetch was across the inter-tidal zone. For the water surfaces encountered at high tide, $z_{0}$ was determined using the relationship described by Zilitinkevich (1969)

$z_{0}=c_{1} \frac{v}{u_{*}}+\frac{u_{*}^{2}}{c_{2} g}$

where $u_{*}$ is the friction velocity, $g$ the acceleration due to gravity, $v$ is the kinematic viscosity, and $c_{1}$ and $c_{2}$ are coefficients with highly variable values estimated to be between $0.0-0.48$ (for $c_{1}$ ), and from $\infty$ to $81.1\left(c_{2}\right)$. In this study intermediate values of $c_{1}=0.1$ and $c_{2}=32.0$ were used. Illustrations of footprint dimensions using this technique can be found in Fig. 13 of McFiggans et al. (2010).

Using this technique, footprints were calculated at five minute intervals throughout the campaign, taking windspeed, tide height and time of day as input parameters. These input parameters are shown in Fig. 4. Emission footprints were also calculated at \pm 5 degrees either side of the wind direction (as measured at the SBR site), and the total modelled footprint was taken to be the mean over all three of these footprint calculations. This averaging procedure aims to compensate for temporal variability in wind direction within each $5 \mathrm{~min}$
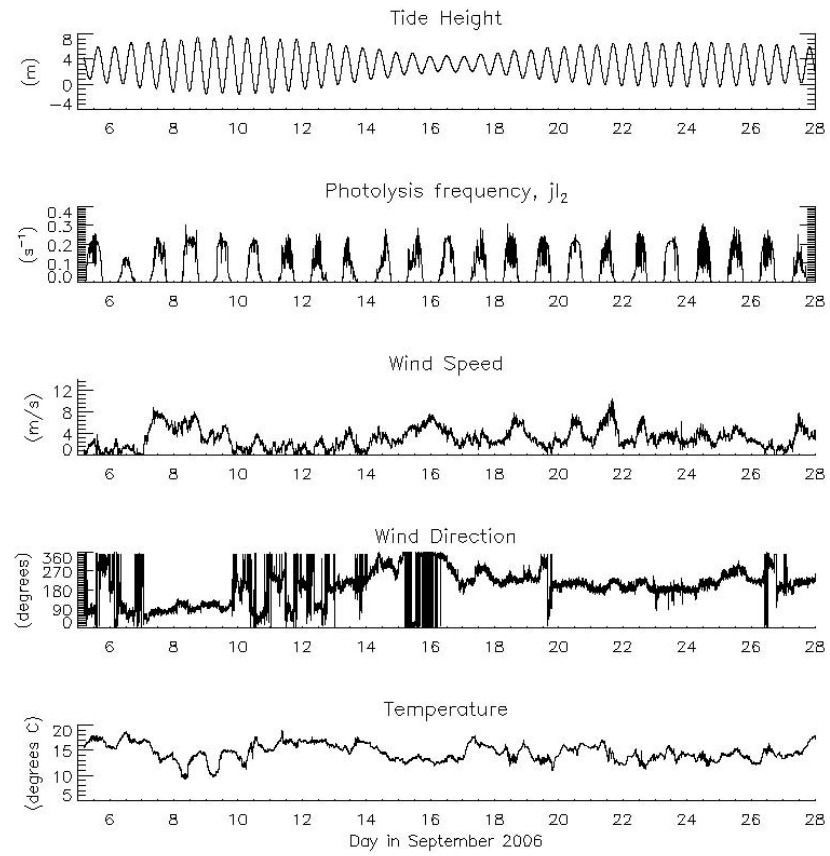

Fig. 4. Tide, $I_{2}$ photolysis frequency and meteorological data used to drive the model.

time bin of the footprint calculation, and for using wind data measured at the SBR site to infer wind direction/speed over the seaweed beds.

Footprints calculated for each different tide height and wind strength were used in the model to characterise the transport of $I_{2}$ emissions to the site and into the LP DOAS instrument's line of sight. Following rotation appropriate to the wind direction, the footprint for each time step was applied to the emissions grid to estimate its contribution to the $\mathrm{I}_{2}$ concentration observed by the BBCRDS and LP-DOAS instruments. Footprints for the LP-DOAS were obtained through integration of all "point" footprints along the line of sight.

\section{Model results}

The exposed regions of macroalgae were calculated for each model time step, and the resultant $\mathrm{I}_{2}$ emissions estimated based on the time since each grid cell had been exposed by the tide and the seaweed species resident within the grid cell. Two example snap-shots of model footprints and emission fields are shown in Figs. 5 and 6. The curtain effect during an ebb tide is shown in Fig. 5, as the initial exposure of the seaweed beds to air causes bursts of high $\mathrm{I}_{2}$ emissions, especially from the most potent emitters (red and green pixels). Emissions are lower and more uniform during the flow tide (see the dark blue pixels in Fig. 6).

Figure 7 shows the total regional emissions (panel 2) and the individual contributions from each seaweed species (panels 3-7). The greatest emissions correlated with the 
Table 1. Derived bathymetry bands for each seaweed species included in this study with assumptions used to derive average fresh weight mass per $\mathrm{m}^{2}$ of coverage. The final column details the height assumption for each species, used to determine the tidal level at which seaweed becomes exposed to the atmosphere.

\begin{tabular}{lcccccc}
\hline Species & $\begin{array}{c}\text { Minimum } \\
\text { depth } \\
(\mathrm{m})\end{array}$ & $\begin{array}{c}\text { Maximum } \\
\text { depth } \\
(\mathrm{m})\end{array}$ & $\begin{array}{c}\text { Average } \\
\text { volumic mass } \\
\left(\mathrm{kgFW} / \mathrm{m}^{3}\right)\end{array}$ & $\begin{array}{c}\text { Average } \\
\text { volume } \\
\left(\mathrm{m}^{3} / \mathrm{m}^{2}\right)\end{array}$ & $\begin{array}{c}\text { Average } \\
\text { biomass } \\
\left(\mathrm{kgFW} / \mathrm{m}^{2}\right)\end{array}$ & $\begin{array}{c}\text { Average } \\
\text { Height } \\
(\mathrm{m})\end{array}$ \\
\hline L. digitata & +0.5 & -1.0 & 320 & 0.03 & 10 & 1.0 \\
L. ochroleuca & 0 & -5.0 & 315 & 0.03 & 10 & 0.5 \\
L. hyperborea & 0 & -20.0 & 310 & 0.03 & 10 & 1.0 \\
Saccharina latissima & +0.5 & -2.0 & 140 & 0.07 & 10 & 0.2 \\
Ascophyllum/Fucus $(35 / 65)$ & +6.0 & +1.5 & 230 & 0.035 & 8 & 0.2 \\
\hline
\end{tabular}

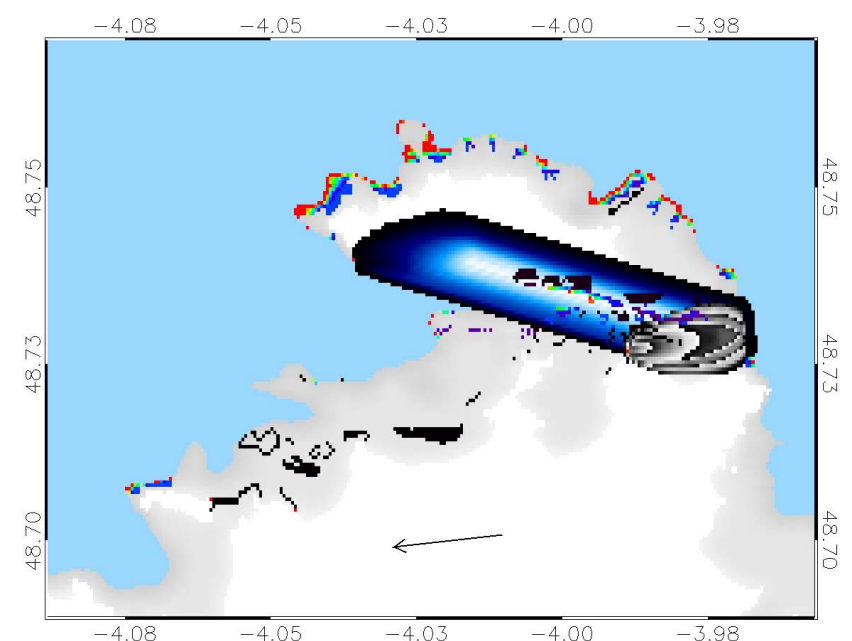

Fig. 5. Model timestep from 10:32 p.m. on 7 September 2006 during an ebb tide, and one of the highest $\mathrm{I}_{2}$ concentrations predicted at site. The wind speed and direction at this time were $5.65 \mathrm{~m} / \mathrm{s}$ and 79.7 degrees respectively, with the tide $0.85 \mathrm{~m}$ below the datum. LP-DOAS and site footprints are shown in blue and grey shading respectively. The modelled $\mathrm{I}_{2}$ emission fields are shown as red, green and dark blue pixels denoting emission rates of $1 \times 10^{17}, 5 \times 10^{16}$ and $2.5 \times 10^{16}$ molecules per grid square per second respectively.

lowest low tides around 9-11 September and 23-25 September when the largest area of L. digitata and particularly $L$. hyperborea beds were uncovered. The dominance of these two Laminaria species in regional emissions is illustrated by the the propensity of green and blue shading in panel 2 of Fig. 7: these two species provide approximately $85 \%$ of total regional emissions over the RHaMBLe campaign period. The shapes of the emission profiles also change with the different tidal spans. The profiles are typically shorter and wider on days with the smallest tidal ranges around the middle of the campaign, as seaweeds growing in shallow waters e.g. fucus and ascophyllum remain uncovered and thus contributing their low level emissions throughout the majority of the tidal cycle. In all cases the emission profiles are asymmetric,

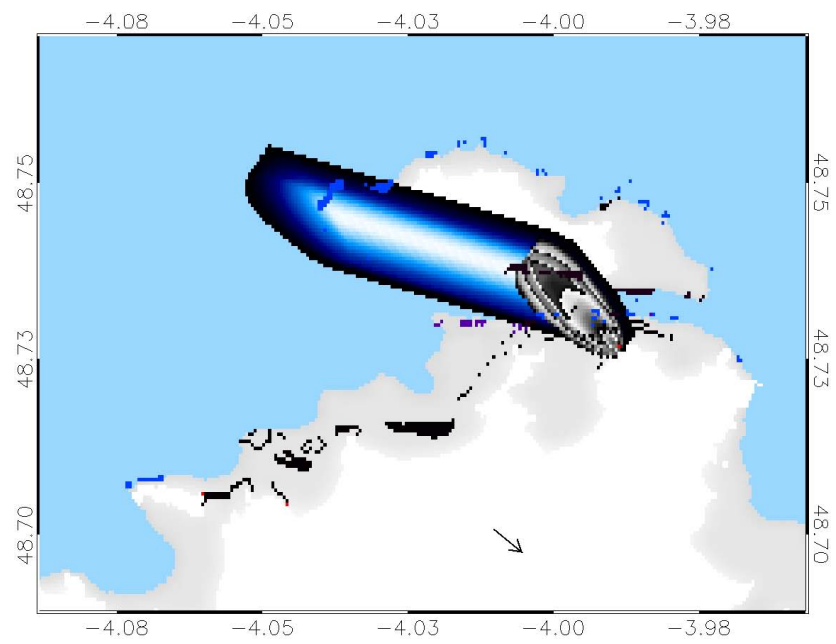

Fig. 6. Model timestep from 5:48 pm on 14 September 2006 during a flow tide, when the BBCRDS instrument measured significant concentrations of $\mathrm{I}_{2}$. The wind speed and direction at this time were $1.9 \mathrm{~m} / \mathrm{s}$ and 309 degrees respectively, with the tide 1.83 metres above the datum. The modelled $\mathrm{I}_{2}$ emission fields are shown on the same scale as Fig. 5 with dark blue, purple and black pixels denoting emission rates of $2.5 \times 10^{16}, 1.25 \times 10^{16}$, and $\leq 5.0 \times 10^{15}$ molecules per grid square per second respectively. The reduction in emissions since first exposure can be seen with respect to Fig. 5

being biased towards greater emissions when the seaweeds are first uncovered by the retreating tide: the initial burst of emissions following first exposure is evident in the contributions of L. ochroleuca and particularly Saccharina latissima (which grows in habitats spanning a narrow depth range).

\section{$4 \quad I_{2}$ measurements during RHaMBLe}

\subsection{BBCRDS measurements}

A broadband cavity ringdown spectrometer was deployed from a shipping container sited on the jetty in front of the SBR, adjacent to the containers housing the campaign's other 


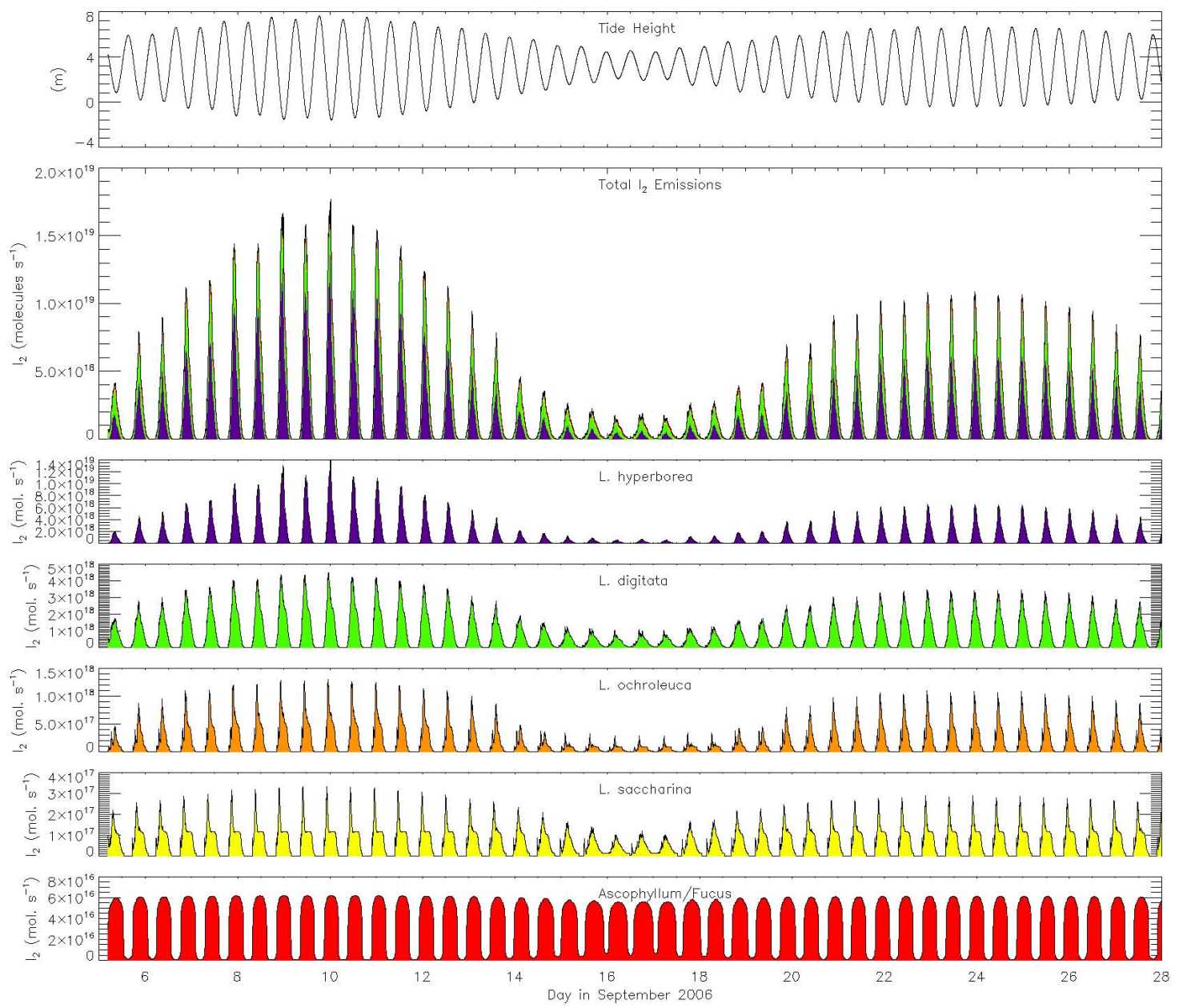

Fig. 7. Tide height (panel 1) and calculated regional emissions of $I_{2}$ from 5 to 28 September 2006 (panel 2). The emission contributions are differentiated according to seaweed species by colour in panel 2, and are plotted separately in panels 3-7.

in situ instruments (McFiggans et al., 2010). Broadband cavity ringdown spectroscopy (BBCRDS) uses light from a pulsed broadband laser to measure the absorption spectrum of samples contained within a high finesse optical cavity (Bitter et al., 2005; Ball and Jones, 2003, 2009). In this case, the BBCRDS instrument was configured to detect molecular iodine using several of the $\mathrm{I}_{2}$ molecule's $\mathrm{B} \leftarrow \mathrm{X}$ absorption bands in the wavelength range $560-570 \mathrm{~nm}$. Other atmospheric gases $\left(\mathrm{H}_{2} \mathrm{O}, \mathrm{NO}_{2}\right.$ and the oxygen dimer $\left.\mathrm{O}_{4}\right)$ also absorb at these wavelengths and thus contribute to the measured BBCRDS spectra.

The BBCRDS system used for this study is based on an instrument previously used to measure $\mathrm{I}_{2}$ at Mace Head (Ireland) during the 2002 NAMBLEX campaign (Saiz-Lopez et al., 2006; Heard et al., 2006) as described in detail by Bitter et al. (2005). In the intervening years, the instrument's performance has been enhanced significantly by upgrading several key components, notably a new laser system that yields pulsed broadband light with a factor of two wider bandwidth at green wavelengths, a new clocked CCD camera and improved analysis software/spectral fitting routines. A broadband dye laser pumped by a $532 \mathrm{~nm} \mathrm{Nd:YAG} \mathrm{laser} \mathrm{(Sirah} \mathrm{Co-}$ bra and Surelight I-20; $20 \mathrm{~Hz}$ repetition rate) generated light pulses with an approximately Gaussian emission spectrum centred at $563 \mathrm{~nm}(\mathrm{FWHM}=5.2 \mathrm{~nm})$. This light was directed into a $187 \mathrm{~cm}$ long ringdown cavity formed by two highly reflective mirrors (Los Gatos, peak reflectivity $=99.993 \%$ at $570 \mathrm{~nm}$ ). Light exiting the ringdown cavity was collected and conveyed through a $100 \mu \mathrm{m}$ core diameter fibre optic cable to an imaging spectrograph (Chromex 250is) where it was dispersed in wavelength and imaged onto a clocked CCD camera (XCam CCDRem2). The time evolution of individual ringdown events was recorded simultaneously at 512 different wavelengths, one for each pixel row of the detector, and light from 50 ringdown events was integrated on the CCD camera before storing the data to a computer. Wavelength resolved ringdown times were produced by fitting the ringdown decay in each pixel row ( $j=1$ to 512$)$. The sample's 
absorption spectrum was then calculated from sets of ringdown times measured when the cavity contained the sample, $\tau\left(\lambda_{j}\right)$, and when flushed with dry nitrogen, $\tau_{0}\left(\lambda_{j}\right)$ :

$$
\begin{aligned}
\alpha\left(\lambda_{j}\right) & =\frac{R_{L}}{c}\left(\frac{1}{\tau\left(\lambda_{j}\right)}-\frac{1}{\tau_{0}\left(\lambda_{j}\right)}\right) \\
& =\sum_{n} \alpha_{n}\left(\lambda_{j}\right)+\alpha_{c o n}\left(\lambda_{j}\right)
\end{aligned}
$$

where $c$ is the speed of light, $\mathrm{R}_{L}$ is the fraction of the cavity that is occupied by absorbing species, $\alpha_{n}\left(\lambda_{j}\right)$ is the wavelength dependent absorption coefficient of the $\mathrm{n}^{\text {th }}$ molecular absorber and $\alpha_{\text {con }}\left(\lambda_{j}\right)$ is the absorption coefficient due to all other contributions to the spectrum's unstructured continuum absorption (mainly aerosol extinction). During the first part of the campaign (before 16 September), the cavity was located inside the shipping container and ambient air was drawn into the cavity at 3 litres per minute. The cavity was then moved onto the roof of the container and operated in an open-path configuration for the remainder of the campaign. In both cases, appropriate corrections (Shillings, 2009) were made to account for exclusion of the atmospheric sample from the cavity's mirror mounts which were purged with dry nitrogen to prevent contamination of the optical surfaces by ambient aerosol particles (i.e. the $\mathrm{R}_{L}$ term in Eq. 2).

BBCRDS absorption spectra were averaged to a time resolution of 5 minutes and the known absorptions due to ambient $\mathrm{H}_{2} \mathrm{O}$ (humidity meter) and $\mathrm{O}_{4}$ (atmospheric oxygen concentration) were subtracted. The concentrations of $\mathrm{I}_{2}$ and $\mathrm{NO}_{2}$ were then retrieved from a multivariate fit of reference absorption cross sections to the structured features remaining in the sample's absorption spectrum using an analysis similar to that developed for DOAS (Platt, 1999; Ball and Jones, 2003, 2009). $\mathrm{NO}_{2}$ cross sections were taken from Vandaele et al. (1996) and were degraded to the $0.12 \mathrm{~nm}$ FWHM instrumental resolution. $\mathrm{I}_{2}$ cross sections were derived from the PGOPHER spectral simulation program (Western, Access: September 2009; Martin et al., 1986) and were scaled to reproduce the differential cross sections reported by SaizLopez et al. (2004) (see also Ball et al. (2010)). The top panel of Fig. 8 shows an example BBCRDS spectrum obtained during the campaign, where the central and lower panels show respectively the $\mathrm{I}_{2}$ and $\mathrm{NO}_{2}$ contributions to the measured absorption overlaid by their fitted reference spectra from the DOAS fitting routine. During the RHaMBLe campaign, the precision of the spectral retrievals was typically $10 \mathrm{pptv}$ (parts per trillion by volume) for $\mathrm{I}_{2}$ and $0.2 \mathrm{ppbv}$ for $\mathrm{NO}_{2}$ ( $1 \sigma$ uncertainty, $304 \mathrm{~s}$ averaging time). Although not the principal target of this deployment, co-retrieval of the $\mathrm{NO}_{2}$ concentrations served as an important quality assurance parameter with which to monitor the BBCRDS instrument's performance. Throughout the campaign, the $\mathrm{NO}_{2}$ concentrations measured by BBCRDS were in excellent quantitative agreement with $\mathrm{NO}_{2}$ measurements made by the University of York's $\mathrm{NO}_{\mathrm{xy}}$ chemiluminescence instrument, as

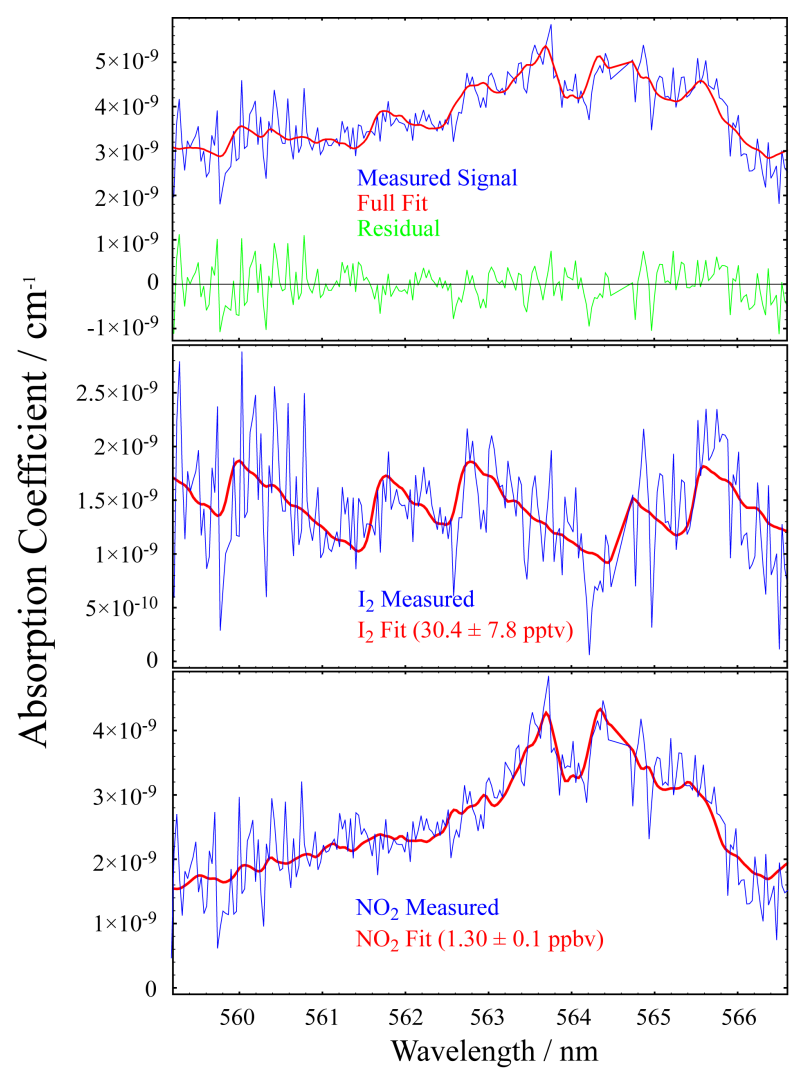

Fig. 8. An example BBCRDS spectrum recorded around 1730 UT on 14 September 2006. The upper panel shows the measured spectrum (blue) after subtraction of the absorptions due to water vapour, $\mathrm{O}_{4}$ and a second order polynomial accounting for the unstructured absorption contributions. The red line shows a DOAS fit to the spectrum's differential structure, and the residual spectrum is shown in green. The measured (blue) and fitted (red) absorption contributions due to $\mathrm{I}_{2}$ and $\mathrm{NO}_{2}$ are shown in the middle and lower panels respectively.

described in McFiggans et al. (2010). The $\mathrm{NO}_{2}$ amounts are also a valuable indicator of the possible extent of $\mathrm{I}_{2}$ recycling via $\mathrm{IONO}_{2}$ chemistry in the semi-polluted environment around Roscoff, and so the $\mathrm{NO}_{2}$ field observations from both instruments are shown together in the figures illustrating the measured and modelled $\mathrm{I}_{2}$ concentrations (see Figs. 10, 12, 16 and 18). The generally good agreement between the BBCRDS and chemiluminescence measurements across a wide range of rapidly varying $\mathrm{NO}_{2}$ concentrations is exemplified by the data from 14-15 September shown in the bottom panel of Fig. 10: the gradient of a correlation plot of the $\mathrm{NO}_{2}$ concentrations recorded by the two instruments was $0.98 \pm 0.03$.

\subsection{Measurements taken by long path DOAS}

During the RHaMBLe Roscoff deployment, the long path differential optical absorption spectroscopy (LP-DOAS) 

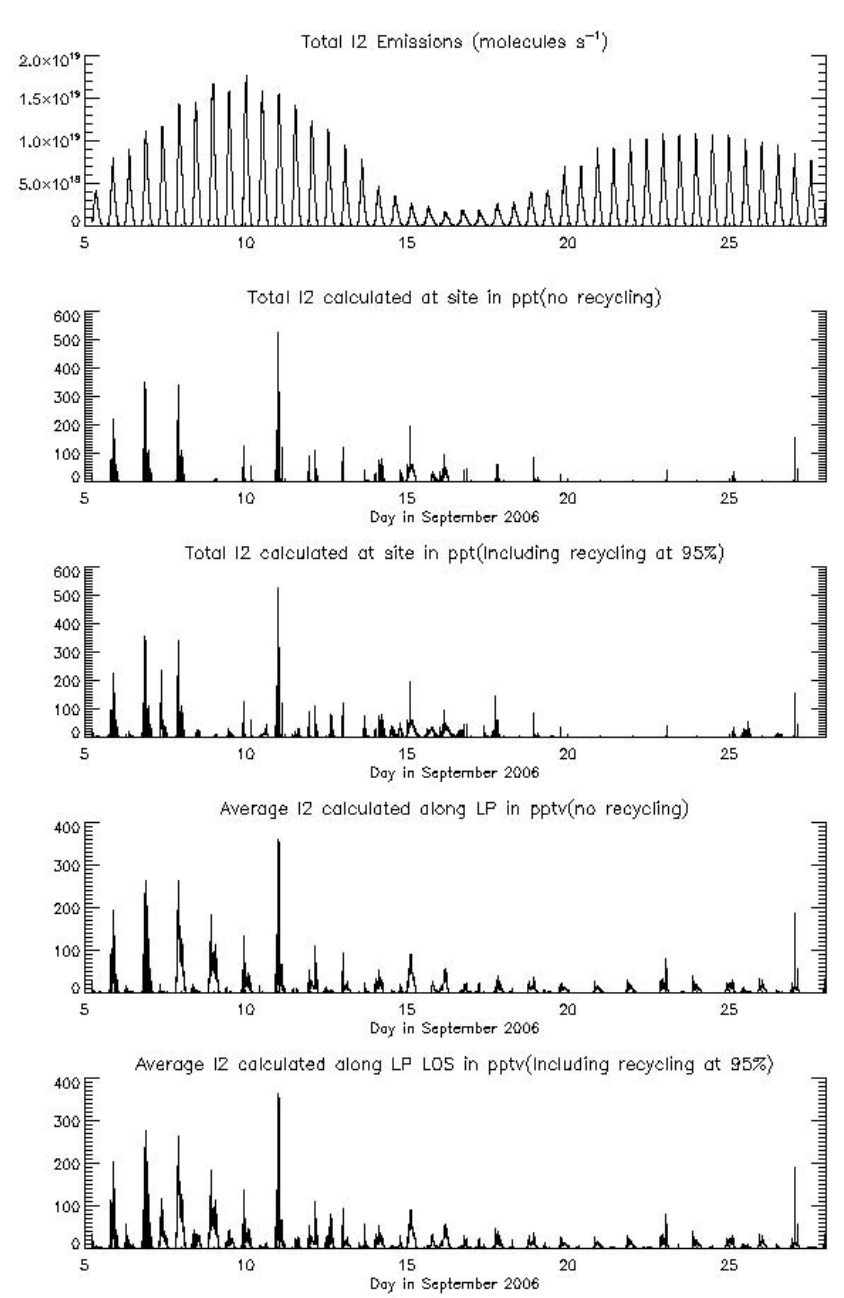

Fig. 9. Complete timeseries of model output from 5 to 28 September 2006. From top down: Regional emissions as calculated by the model; $\mathrm{I}_{2}$ concentrations at the measurement site based on footprint analysis calculated with photolytic destruction and no recycling processes; likewise but with recycling at $95 \%$. The lowest two panels show calculated $\mathrm{I}_{2}$ concentrations along the LP-DOAS line of sight with photolytic destruction and no recycling processes, and with recycling at $95 \%$.

technique (Plane and Saiz-Lopez, 2006) was used to measure the concentrations of $\mathrm{I}_{2}, \mathrm{OIO}, \mathrm{IO}$ and $\mathrm{NO}_{3}$. The absorption path extended $3.35 \mathrm{~km}$ from the SBR (48.728 latitude, -3.988 longitude), to a small outcrop on the south west shore of the Ile de Batz (48.74 latitude, -4.036 longitude), where a retroreflector array was placed to fold the optical path - see also Fig. 1. The total optical path length was thus $6.7 \mathrm{~km}$ with the beam 7 to $12 \mathrm{~m}$ above the mean sea level. Full details of the DOAS instrument can be found elsewhere (Mahajan et al., 2009; Saiz-Lopez and Plane, 2004).

Briefly, spectra were recorded with $0.25 \mathrm{~nm}$ resolution before being converted into differential optical density spectra. The contributions of individual absorbing species to the

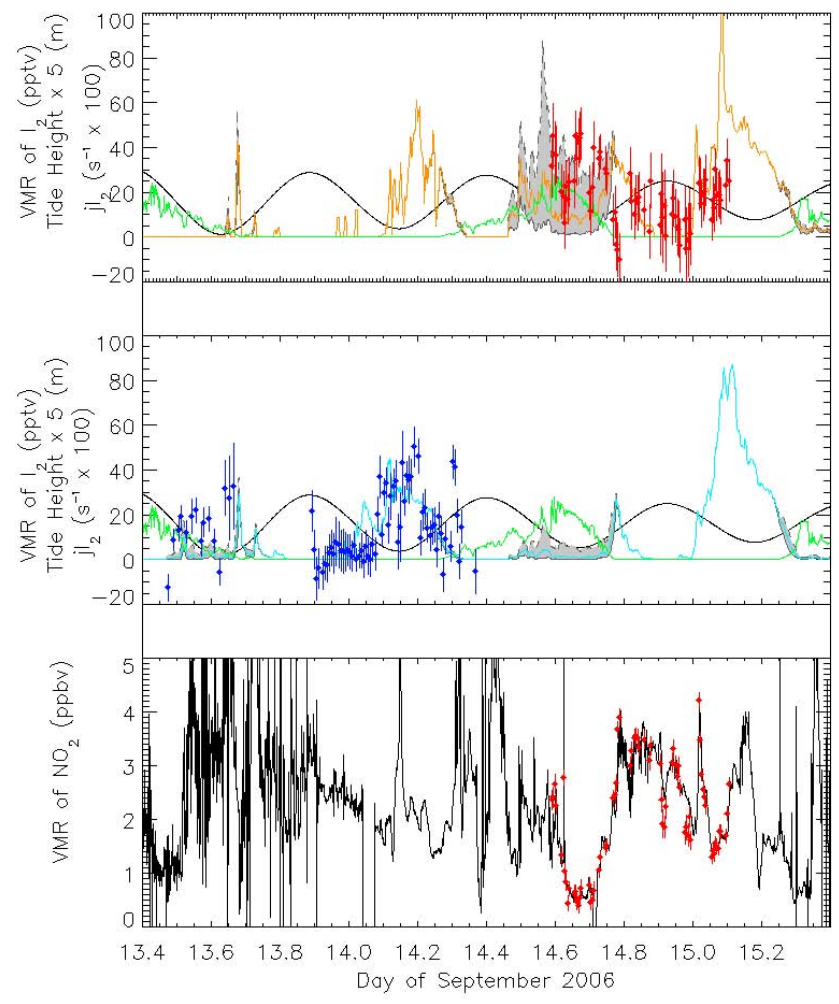

Fig. 10. Modelled and measured data from 13 to 15 September 2006. The top panel shows BBCRDS data (red points and error bars) with modelled concentrations of $\mathrm{I}_{2}$ at the site assuming $95 \%$ recycling of $I_{2}$ photolysed during the daytime (orange line). The middle panel shows LP-DOAS data (dark blue points and error bars) with modelled concentrations of $\mathrm{I}_{2}$ in the LP-DOAS light path assuming $95 \% \mathrm{I}_{2}$ recycling (blue line). The grey areas in the upper two plots indicate the range of modelled $\mathrm{I}_{2}$ values using recycling assumptions from $R=90 \%$ to $98 \%$. The photolysis frequency of $\mathrm{I}_{2}$ is indicated by the green line in the upper two plots, and tide by the black line. The bottom panel shows $\mathrm{NO}_{2}$ measured by the $\mathrm{NO}_{\mathrm{xy}}$ chemiluminescence (black) and BBCRDS instruments (red points and error bars).

measured spectrum were determined by simultaneous fitting of their molecular absorption cross sections using singular value decomposition (Plane and Saiz-Lopez, 2006). Averaged $\mathrm{I}_{2}$ concentrations along the line of sight were retrieved in the 535-575 nm window on a number of days and nights using the $\mathrm{I}_{2}$ absorption cross sections of Saiz-Lopez et al. (2004). The full data set from the LP-DOAS instrument is presented in Mahajan et al. (2009) and McFiggans et al. (2010).

For the present work, footprints for the LP-DOAS instrument were calculated using the same footprint model (assuming an $8 \mathrm{~m}$ height for the LP-DOAS light beam), with modelled $\mathrm{I}_{2}$ amounts averaged for the footprints along the line of sight. In this way the model provides a path length averaged measurement of $I_{2}$ along the LP-DOAS light path which sampled emissions from a significant proportion of the 
channel between the SBR and the Ile de Batz (see, for example, the footprints in Figs. 5 and 6).

\section{Calculation of total emissions and modelled $I_{2}$ at the site and along the LP DOAS line of sight}

Spatially resolved emissions were calculated for each grid square within the model for each one minute time step. Site and LP-DOAS footprints were calculated taking account of wind speed, wind direction, and tidal height. The time taken for $\mathrm{I}_{2}$ emissions to travel from their source within the footprint to the detector was estimated from the windspeed measured at the site. In addition to dilution of the emitted $\mathrm{I}_{2}$ (accounted for in the footprint), the model also considered the photolytic destruction of $I_{2}$ during its transit to the measurement location using equation 3 :

$\left[\mathrm{I}_{2}\right]_{(t)}=\left[\mathrm{I}_{2}\right]_{(0)} e^{j \mathrm{I}_{2} \cdot t}$

where $\left[\mathrm{I}_{2}\right]_{(t)}$ is the volume mixing ratio of $\mathrm{I}_{2}$ at time $t$, and $\left[I_{2}\right]_{(0)}$ is the volume mixing ratio of $I_{2}$ at time 0 directly above the emission source. $\mathrm{jI}_{2}$ is the photolysis frequency of $I_{2}$ as measured by a spectral radiometer.

Although no chemical modelling was attempted along the lines of Mahajan et al. (2009), a simple recycling parameter $R$ was also included in this work to mimic the effects of $\mathrm{I}_{2}$ recycling via $\mathrm{IONO}_{2}$ chemistry downstream of the emission source. This recycling was achieved through modification of the $\mathrm{I}_{2}$ photolytic destruction process to:

$\left[\mathrm{I}_{2}\right]_{(t)}=\left[\mathrm{I}_{2}\right]_{(0)} e^{j \mathrm{I}_{2} \cdot(1-R) \cdot t}$

The recycling parameter $R$ effectively permits a proportion of photodissociated $I_{2}$ to be instantly reformed in our model. In order to test this approach, the chemical model presented previously in Mahajan et al. (2009) was re-run in this study to examine the decay of $\mathrm{I}_{2}$ concentrations downwind of an emission source. The chemical model was run twice; once in the presence of $\mathrm{NO}_{\mathrm{x}}$ (for an assumed baseline $\mathrm{NO}_{2}$ concentration of $2 \mathrm{ppbv}$ ), and again in the absence of $\mathrm{NO}_{\mathrm{x}}$ but for reduced $\mathrm{I}_{2}$ photolysis rates (whilst keeping the photolysis rates of other photolabile species unchanged). Good qualitative and reasonable quantitative agreement was found between these two scenarios when the $\mathrm{I}_{2}$ photolysis rate was decreased to $10 \%$ of its typical daytime value, providing a validation for our simplistic approach of reducing the effective $\mathrm{I}_{2}$ photolysis rates to mimic the effect of $\mathrm{I}_{2}$ recycling via $\mathrm{IONO}_{2}$ formation in this semi-polluted atmosphere. For the present modelling study, the recycling parameter was set to a default value of $R=0.95$, i.e. $95 \%$ of the $\mathrm{I}_{2}$ that is photolysed is reformed by subsequent chemistry. This is higher than the $R=0.90$ suggested by the Mahajan et al. (2009) chemical modelling, but tended to produce the best agreement with the observational data. For comparison, modelled $\mathrm{I}_{2}$ concentrations were also calculated for smaller $(R=0.90)$ and larger
( $R=0.98$ ) recycling efficiencies appropriate for, respectively, $\mathrm{NO}_{2}$ concentrations at and above the $\mathrm{NO}_{2}=2$ ppbv baseline case of the Mahajan et al. (2009) model. These results are additionally shown in Fig. 10 and the following other results figures.

Figure 9 shows total calculated regional emissions, the modelled $\mathrm{I}_{2}$ mixing ratios in air advected to the measurement site (BBCRDS) and the mean $\mathrm{I}_{2}$ mixing ratio in the air sampled along the LP-DOAS line of sight. Modelled emissions in the middle and bottom panels assume $95 \%$ recycling of photolysed $\mathrm{I}_{2}$ during the daytime. Fig. 9 considers two $\mathrm{I}_{2}$ loss scenarios: (i) dilution and irreversible photolytic loss according to Eq. (3) and (ii) dilution and photolytic loss less a recycling assumption at $R=0.95$ as per Eq. (4). The modelled and measured $\mathrm{I}_{2}$ concentrations are compared in the following section.

\section{Comparison of modelled and measured $I_{2}$}

Owing to the challenges inherent in operating the BBCRDS and LP-DOAS instruments in the field and the requirements for measurements of other species to be taken by the same instrumentation, $I_{2}$ observations are unfortunately not available throughout the campaign. Results from three intensive measurement periods from each instrument are detailed below.

\subsection{Comparisons during the night}

During the night, in the absence of photolytic destruction, $\mathrm{I}_{2}$ can be considered as a passive tracer to establish the link between emissions and measurements. Agreement between the model and BBCRDS and LP-DOAS measurements at night indicates acceptable model parameterisation of emission rates, seaweed spatial distribution, meteorology, and dilution and dispersion within the emission footprint. This can therefore be used as a baseline for investigations during the day when additionally photolytic destruction and chemical recycling of $\mathrm{I}_{2}$ become important.

Figure 10 illustrates night-time measurements and model data from 13 to 15 September, while Fig. 11 shows the corresponding sources of $\mathrm{I}_{2}$ (differentiated by seaweed species) modelled at the measurement site and along the LP-DOAS light path. In Fig. 10 the diurnal cycle is indicated by the photolysis frequency of $I_{2}$ (green line), with tide heights shown in black. During the period described in Fig. 10, there were night-time low tides shortly after midnight on 14 and 15 September 2006 when, respectively, both the LP-DOAS and BBCRDS observed $\mathrm{I}_{2}$ substantially above their detection limits and the model predicted peak $I_{2}$ concentrations of $50-100$ pptv.

Three modelled $\mathrm{I}_{2}$ datasets are presented in Fig. 10 (and other following data figures), covering the range of $I_{2}$ recycling assumptions discussed in the previous section. $\mathrm{I}_{2}$ 

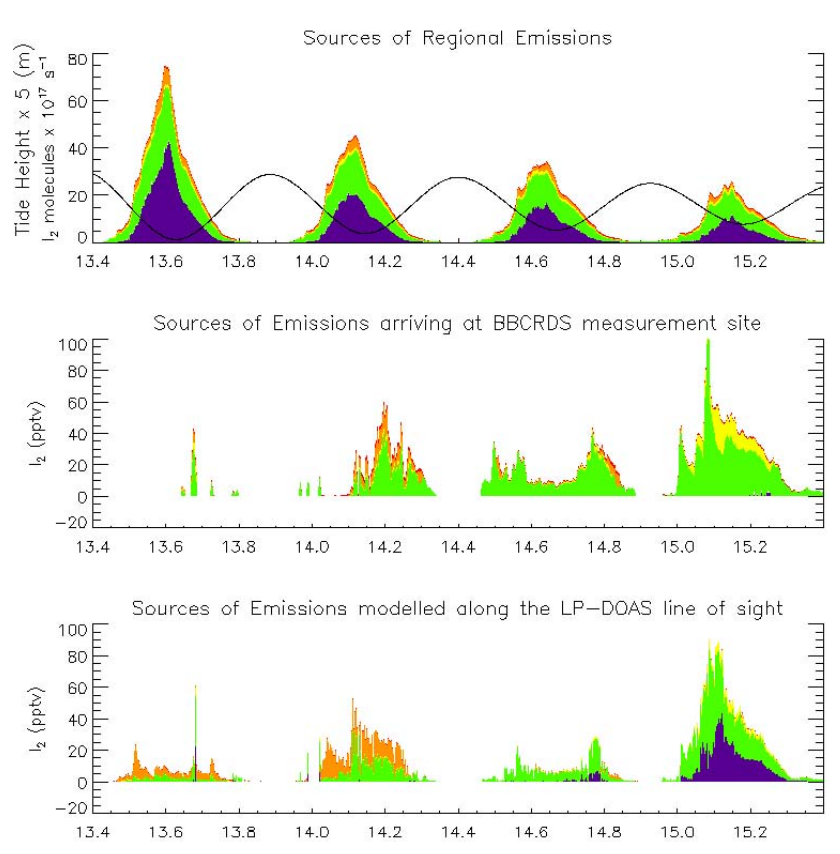

Fig. 11. Sources of emissions for 13 to 15 September 2006. The top panel shows total regional emissions, data in the middle panel indicates the source of $\mathrm{I}_{2}$ emissions modelled at the measurement site, with the bottom panel showing the source of $\mathrm{I}_{2}$ emissions modelled along the LP-DOAS line of sight. Modelled emissions in the middle and bottom panels assume $95 \%$ recycling of photolysed $\mathrm{I}_{2}$ during the daytime. The emissions are coloured by seaweed species using the convention of Fig. 7

concentrations modelled at the measurement site for our usual assumption of $95 \%$ recycling of photolysed $\mathrm{I}_{2}$ are indicated by the orange line. The lower boundary of the grey region defines modelled $\mathrm{I}_{2}$ concentrations for the $R=0.90$ recycling assumption, in line with results from the Mahajan et al. (2009) chemical recycling scheme. The upper boundary of the grey region is defined by a $R=0.98$ recycling scheme. The purpose of the grey region is to indicate reasonable boundaries of uncertainty in the model output introduced by recycling schemes which allow between 90 and $98 \%$ of photodisocciated $\mathrm{I}_{2}$ to be reformed through $\mathrm{IONO}_{2}$ chemistry. During the night, there is no photolysis and no $\mathrm{I}_{2}$ recycling via $\mathrm{IONO}_{2}$ chemistry, and thus setting $R$ to any value $0.00-1.00$ yields an identical result: at night, the grey region collapses to the orange line alone. Similar considerations apply to the blue line modelling the LP-DOAS measurements (for $R=0.95$ ) and the accompanying grey region $(0.90<R<0.98)$.

The dominant contributions from L. digitata and $L$. hyperborea to the regional $\mathrm{I}_{2}$ emissions are highlighted in the top panel of Fig. 11. The asymmetry of emission profiles throughout the low tide cycle is also evident, resulting from the decay in seaweed plants' $I_{2}$ emission rates with time since their first exposure to the atmosphere. In contrast

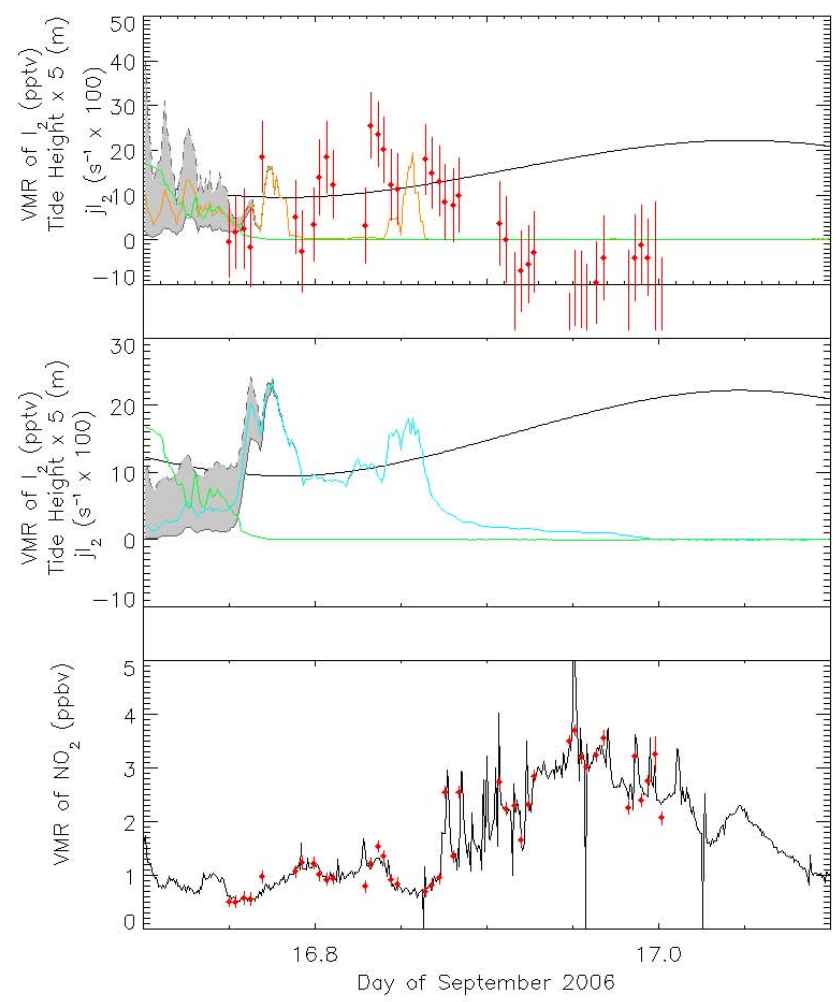

Fig. 12. Modelled and measured (BBCRDS) data from 16 September 2006 with format as per Fig. 10.

to the regional results in the top panel, the contribution of each seaweed species' emissions to the $\mathrm{I}_{2}$ measured by the BBCRDS or LP-DOAS technique is highly dependent upon wind direction and speed (middle and lower panels of Fig. 11). For example, the lack of a contribution from L. hyperborea to the BBCRDS modelled data is a common feature throughout the dataset, resulting from the absence of L. hyperborea seaweed beds in the shallower waters near to the measurement site, while the extensive and strongly emitting L. hyperborea beds around the Ile de Batz and on the coast west of Roscoff lie too far away to be included in the footprint of air advected to the SBR site. The LP-DOAS does however have sensitivity to L. hyperborea emissions from an area of this species growing to the south-west of the Ile de Batz.

Measured night-time concentrations of $I_{2}$ around the predawn low tide on 14 September (up to $50 \mathrm{pptv}$ ) are some of the highest recorded by the LP-DOAS instrument for the whole campaign, and are shown in Fig. 10 to be reproduced well by the modelling results. Agreement between the BBCRDS observations and the model from 14 to 15 September is also acceptable, with the model reproducing the main form of the BBCRDS measurements through to the early hours of 15 Semptember (albeit the sharp $\mathrm{I}_{2}$ peak of approx. $100 \mathrm{pptv}$ due to L. digitata emissions predicted by the model towards the end of the time series is not present 

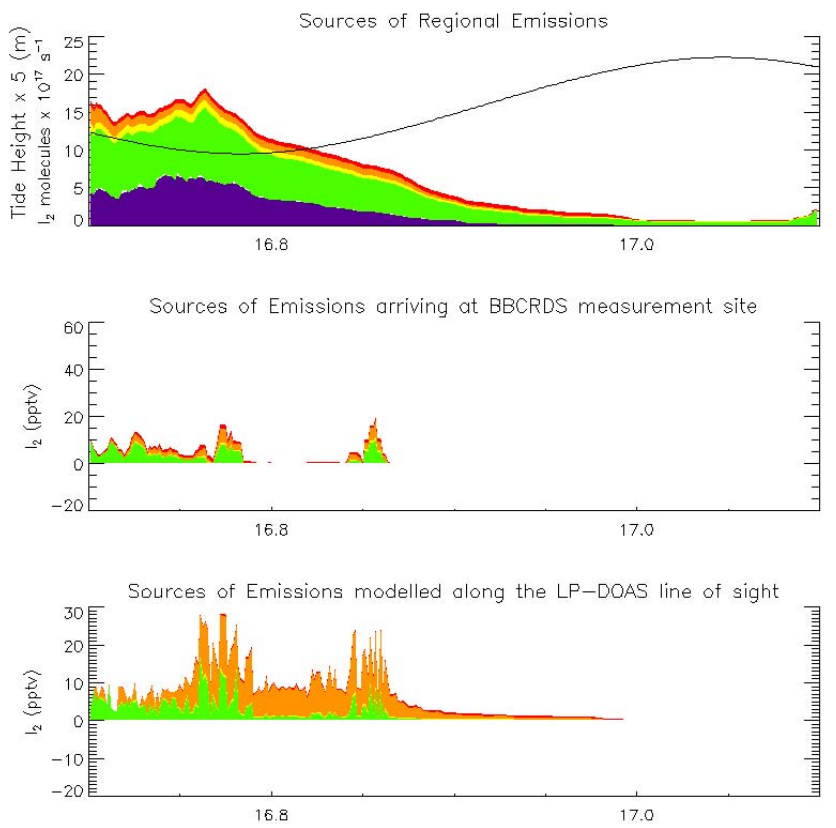

Fig. 13. Sources of emissions for 16 September 2006 with format as per Fig. 11.

in the BBCRDS measurement). The close correlation of the $\mathrm{NO}_{2}$ measurements by the $\mathrm{NO}_{\mathrm{xy}}$ and BBCRDS systems suggests good operation of both instruments during this period, and thus any measured/modelled discrepancy for $\mathrm{I}_{2}$ is more likely due to deficiencies of the model.

Night-time measurements and model results are also illustrated in Figs. 12 and 13 for 16 September, when regional emissions from predominantly L. digitata are predicted around the evening-time low tide. $\mathrm{I}_{2}$ concentrations up to 25 pptv (significantly above the BBCRDS instrument's limit of detection) were indeed seen around the low tide, with the measured $\mathrm{I}_{2}$ concentrations decreasing to zero at midnight as the tide rises. The model $\mathrm{I}_{2}$ concentrations peak at approximately $20 \mathrm{pptv}$ around low tide and then decay away to zero in broad agreement with the measurement. However, the modelled $\mathrm{I}_{2}$ is more highly structured than the measurement, indicating a high spatial dependence (i.e. wind direction) of the $I_{2}$ emissions reaching the measurement site (see also middle panel of Fig. 13). Throughout the 16 September dataset, the BBCRDS $\mathrm{NO}_{2}$ measurements are again in excellent agreement with the $\mathrm{NO}_{\mathrm{xy}}$ chemiluminesence instrument, providing confidence that the BBCRDS observational data is valid. The model also predicts sustained $\mathrm{I}_{2}$ emissions from L. ochroleuca in the LP-DOAS line of sight (bottom panel of Fig. 13 and middle panel of Fig. 12), though unfortunately no LP-DOAS measurements of $I_{2}$ were available on this night.

Measurements and modelled $\mathrm{I}_{2}$ concentrations from early in the campaign, on 5 September, are shown in Figs. 14 and 15. Although there is no $\mathrm{NO}_{2}$ data for this period (to comment on the possible extent of $\mathrm{I}_{2}$ recycling), and no meteorological data for the first few hours with which to pro-
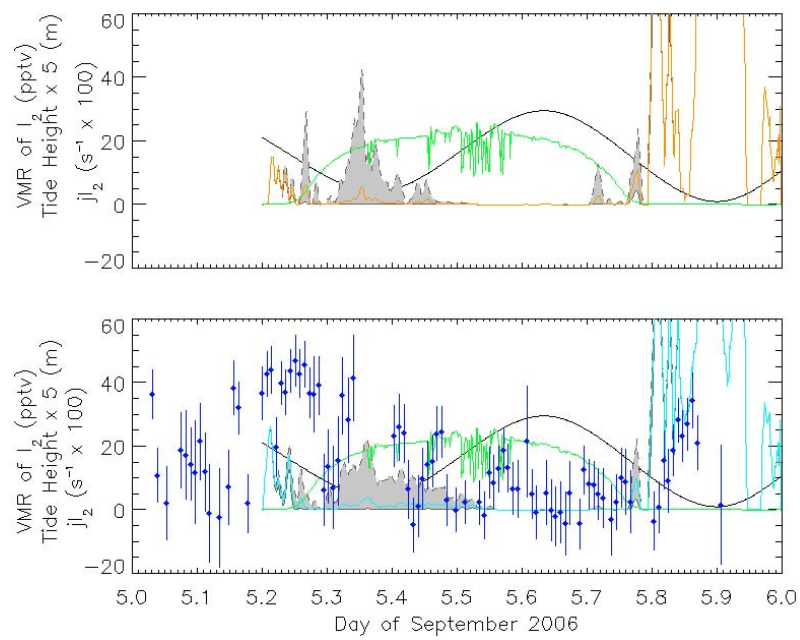

Fig. 14. Modelled and measured (LP-DOAS) data from 5 September 2006 with format as per Fig. 10.
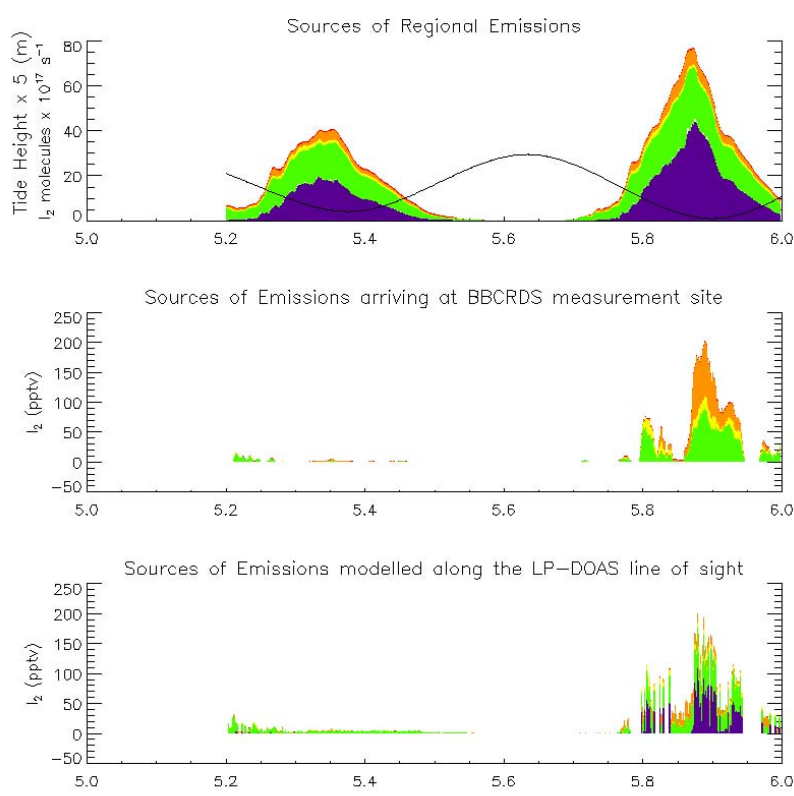

Fig. 15. Sources of emissions for 5 September 2006 with format as per Fig. 11.

duce modelled $\mathrm{I}_{2}$ before 5 a.m., this dataset illustrates a number of interesting features. Pre-dawn concentrations of $I_{2}$ are both predicted and seen along the LP-DOAS line of sight. Up to 40 pptv of $I_{2}$ is detected by LP-DOAS around the early morning low tide, when the model also predicts up to $20 \mathrm{pptv}$ of $\mathrm{I}_{2}$ before dawn and post-dawn for the the most extensive $R=0.98$ recycling regime. The modelled and measured $\mathrm{I}_{2}$ then both decrease to essentially zero as the tide rises from its minimum in mid-morning, through into the afternoon. After dusk, as the tide again recedes, both modelled and measured concentrations increase significantly. It should be noted that emissions from $L$. hyperborea are responsible for the largest 
modelled concentrations at the end of this day (see Fig. 15). These are emitted into the LP-DOAS light path as it passes close to the L. hyperborea seaweed bed south west of the Ile de Batz.

\subsection{Comparisons during the day}

$\mathrm{I}_{2}$ photolyses rapidly during the day, with $\mathrm{I}_{2}$ photolysis rates reaching $0.25 \mathrm{~s}^{-1}$ at solar noon (Fig. 4) corresponding to a lifetime of only $4 \mathrm{~s}$ for $\mathrm{I}_{2}$. Transport times from all but the very closest seaweed beds are equivalent to many photolytic lifetimes and thus photolytic destruction rapidly reduces $\mathrm{I}_{2}$ concentrations modelled after dawn to negligible amounts. Indeed without a method for reforming photolysed $\mathrm{I}_{2}$, the model predicts that no $\mathrm{I}_{2}$ should be detectable either at the site or by the LP-DOAS instrument for the vast majority of daylight hours (note, for example, the differences between the modelled daytime $I_{2}$ concentrations shown in panels 2 and 3 and panels 4 and 5 of Fig. 9). However, both LP-DOAS and BBCRDS techniques clearly do measure appreciable concentrations of $\mathrm{I}_{2}$ around most of the daytime low tides when the instruments were making $I_{2}$ observations, suggesting a significant mechanism to reform $\mathrm{I}_{2}$ must be present. The modelling of recycling schemes from $R=90$ to 98 presents an opportunity to assess the likely extent of recycling required for the model to reproduce the observations, and to relate the extent of recycling to the $\mathrm{NO}_{2}$ concentrations co-measured by the BBCRDS and $\mathrm{NO}_{\mathrm{xy}}$ instruments.

Modelled concentrations and observational data around the daytime low tide on 25 September are shown in Fig. 16. Rather low concentrations of $\mathrm{I}_{2}$ are predicted on this day, with concentrations reported by the BBCRDS instrument consistently below its detection limit for $\mathrm{I}_{2}$, including at the tidal minimum. Some of the lowest $\mathrm{NO}_{2}$ concentrations of the whole campaign were also measured by the BBCRDS and $\mathrm{NO}_{\mathrm{xy}}$ instruments on this day, being approximately 0.5 pptv for the duration of the BBCRDS observations (bottom panel). This is significantly below the $2 \mathrm{pptv}$ of $\mathrm{NO}_{2}$ considered by the Mahajan et al. (2009) chemical model of $\mathrm{I}_{2}$ recycling via $\mathrm{IONO}_{2}$ which suggested the recycling parameter was around $R=0.90$. For the particularly clean conditions (for this location) of 25 September, with $\mathrm{NO}_{2}$ significantly below 2 pptv, recycling is likely to be ineffective at offsetting the rapid photolytic losses of $\mathrm{I}_{2}$. Therefore the most reasonable modelled $\mathrm{I}_{2}$ concentrations are likely to lie below the grey region (i.e. below even the $R=0.90$ assumption), commensurate with the low $I_{2}$ amounts reported by the BBCRDS instrument. The exception is the spike of 2575 pptv $\mathrm{I}_{2}$ (depending on where $R$ is assumed in the range 0.90 to 0.98 ) due to a sharp rise in modelled $L$. digitata emissions received at the site caused by a short-lived shift in wind direction (see Fig. 17), but which is not evident in the BBCRDS measurements themselves.

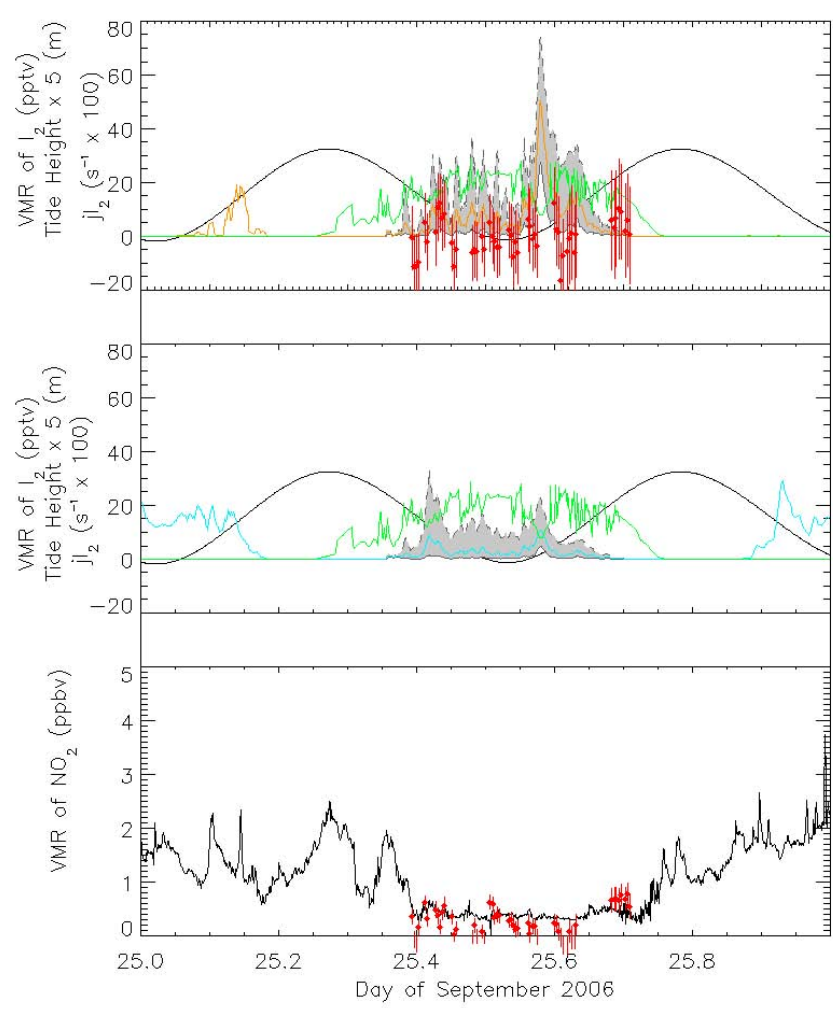

Fig. 16. Modelled and measured (BBCRDS) data from 25 September 2006 with format as per Figure 10.
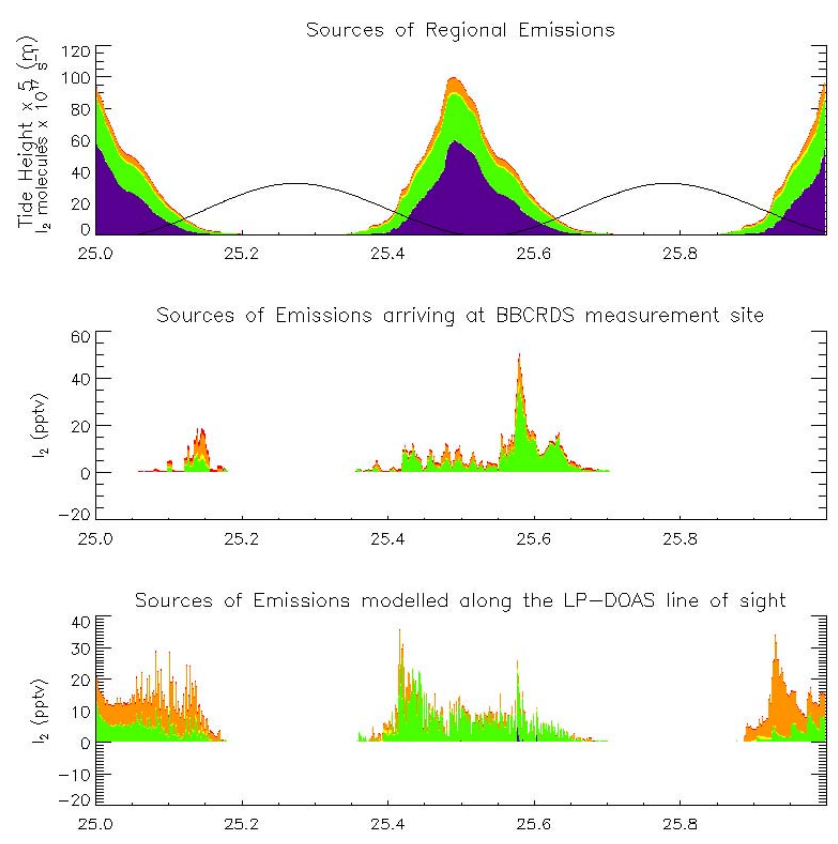

Fig. 17. Sources of emissions for 25 September 2006 with format as per Fig. 11. 


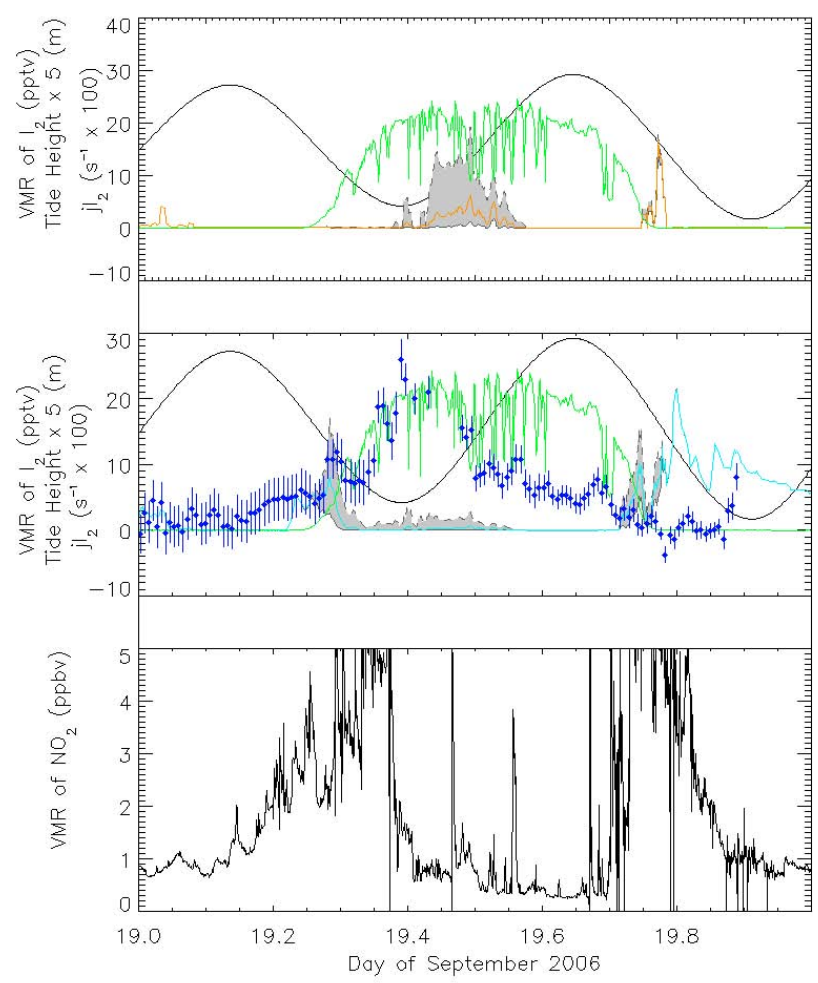

Fig. 18. Modelled and measured (LP-DOAS) data from 19 September 2006 with format as per Fig. 10.

Daytime data from 14 September, included in Fig. 10 and introduced above, indicate broad agreement between BBCRDS measurements and modelled concentrations at site, within the boundaries established by the $R=0.90$ to 0.98 recycling schemes. It should be noted here that although $\mathrm{NO}_{2}$ concentrations at site experienced a local minimum of under 1 ppbv around the time of the highest BBCRDS $\mathrm{I}_{2}$ concentrations, the usual $\mathrm{NO}_{2}$ concentrations on this day are substantially higher than on clean days such as 25 September (Fig. 16), and significant recycling is still needed to bring the model into agreement with the BBCRDS measurements. The modelled $\mathrm{I}_{2}$ concentrations during daylight hours on the previous day, 13 September, are generally smaller than the LP-DOAS measurements (see middle panel of Fig. 10), although there are spikes in the modelled $\mathrm{I}_{2}$ around sunset of a similar size to the observations. Indeed, there is a particularly large amount of variability in the modelled and measured $\mathrm{I}_{2}$ concentrations, measured $\mathrm{NO}_{2}$ and emission sources on 13 September, most likely due to highly variable wind conditions on this day.

For completeness, LP-DOAS data from 19 September are shown in Fig. 18. There is generally good agreement between the data and model during the first phase of this time period, i.e. a very low level of $I_{2}$ is observed from midnight until the tide ebbs around dawn, when 10 pptv of $I_{2}$ is observed and modelled. There is then poor agreement for the majority of the day despite high data density and relatively low error estimates on the LP-DOAS data: the LP-DOAS system detects $\mathrm{I}_{2}$ well above its detection limit throughout daylight hours which is not reproduced in the model.

\subsection{Discussion of differences}

This modelling activity has demonstrated a number of strong correlations between modelled and measured $\mathrm{I}_{2}$ concentrations for both measurement geometries, and provided information on the likely $I_{2}$ sources (seaweed speciation and geographical location). However, significant discrepancies remain, most notably those on 19 September for the longest LP-DOAS data sequence, indicating inaccuracies in model inputs and/or more fundamental limitations of the modelling approach applied in this work.

Potentially inaccurate input data include the spatial distribution of seaweed species, including small patches of seaweed not accurately represented by or missing from the original seaweed maps (Braud, 1974; Bajjouk et al., 1996), mixed seaweed beds containing more than one species, and any loose seaweed that had washed up on the shore near to measurement site. Although previous studies were used to produce an updated map for the present modelling study, an aerial survey coupled with further surface studies would reduce uncertainties in this area. Furthermore, there are no $\mathrm{I}_{2}$ emission data available for L. ochroleuca from previous laboratory studies. Here this species was assumed to emit at a rate intermediate between $L$. digitata/L. hyperborea and Saccharina lattisima, but if this assumption is in error it could have a significant impact on modelled $\mathrm{I}_{2}$ amounts, particularly for the LP-DOAS measurement geometry where L. ochroleuca is the dominant emission source for certain meteorological conditions (see Fig. 13 for example). Also, the spatial variability of wind fields across the eulittoral zone is not considered in detail in this study. Although two independent measurements of wind speed and direction were taken at the BBCRDS measurement site, and showed strong agreement, the local scale topography is likely to have caused a some variation in wind vectors within the eulittoral zone. In particular, variability in wind vectors increase uncertainties in the contributions made by the Laminaria beds around the Ile de Batz. For example, emissions from these seaweeds are responsible for the large spikes in modelled $\mathrm{I}_{2}$ concentrations above 100 pptv shown in Fig. 9, and which are generally not replicated in the measurements (i.e. the modelled $\mathrm{I}_{2}$ footprints are likely to be too directional, even with \pm 5 degree uncertainty already assumed in the model).

Fundamental limitations in our the relatively simplistic modelling include the parameterisation of seaweed mass per unit sea surface area and characterisation of the surface roughness and slope in the footprint modelling. Drawing conclusions about the extent of daytime $\mathrm{I}_{2}$ recycling and its relationship with $\mathrm{NO}_{2}$ concentrations also rely on an understanding of the concentration of $\mathrm{NO}_{2}$ above the eulittoral zone and along the full transport path of $\mathrm{I}_{2}$. A comprehensive 
modelling treatment for this factor demands a more advanced chemical scheme and a robust understanding of iodine chemistry in the semi-polluted environment (Mahajan et al., 2009). As with the wind vectors, $\mathrm{NO}_{2}$ concentrations measured at site are not fully representative of $\mathrm{NO}_{2}$ concentrations throughout the modelled region of interest with its many varied $\mathrm{NO}_{\mathrm{x}}$ sources.

Of the potential sources of error discussed here, we suggest the major contributors to model/measurement differences are inaccuracies in mapping the spatial distributions of seaweed habitats (particularly for seaweeds close to measurement locations), uncertainties in L. ochroleuca emission rates, and the variability in wind vectors along the transit path from emission source to detection. Given the close agreement between $\mathrm{NO}_{2}$ measurements from the $\mathrm{NO}_{\mathrm{xy}}$ and BBCRDS instruments, and the established pedigree of LPDOAS as an atmospheric measurement technique, coupled with high data density and low error bars calculated from the DOAS fits, inaccuracies in the measurements are not considered to be a significant reason for any discrepancy with the modelled data.

\section{Conclusions}

A dynamical model was produced to examine the sensitivity of in situ and line of sight measurements based at the Station Biologique de Roscoff to regional emissions of molecular iodine during the RHaMBLe campaign in September 2006. Modelled concentrations of $\mathrm{I}_{2}$ were compared to measured concentrations from a BBCRDS instrument located on the shore, and a LP-DOAS instrument with an absorption path extending over the eulittoral zone. Although having simplifying assumptions, this model nevertheless provides a means to assess likely impacts on measured $I_{2}$ concentrations from time-dependent variations in emissions from the different seaweed species growing in the area and the spatial location of seaweed beds relative to the measurement locations. Furthermore, the boundaries of feasible $\mathrm{I}_{2}$ recycling schemes suggested by our measurements and by recent chemical modelling studies were explored.

Using previous laboratory measurements of speciesdependent $\mathrm{I}_{2}$ emission rates, concentrations of $\mathrm{I}_{2}$ above the most strongly emitting L. hyperborea and L. digitata beds were predicted to be $15 \mathrm{ppbv}$ immediately after being first exposed to the atmosphere by a retreating tide in line with recent laboratory measurements (Ball et al., 2010). Although a few spikes above 100 pptv were predicted, concentrations at the BBCRDS measurement site and along the LP-DOAS line of sight were generally modelled to be below $50 \mathrm{pptv}$, and show some quantitative agreement with measured datasets. This demonstrates the use of concentration footprints in this context to explore the substantial dispersion and dilution along a transit path linking the high concentrations directly above emission sources to the much lower concentrations measured downwind.
Modelled concentrations during the day were demonstrated to be highly sensitive to recycling schemes allowing the reformation of photodissociated $\mathrm{I}_{2}$. Without any recycling mechanism, concentrations of $\mathrm{I}_{2}$ modelled for both measurement geometries would usually have been negligible, in marked contrast to the BBCRDS and LP-DOAS observations themselves which both report clear daytime $\mathrm{I}_{2}$ signals above their detection limits (approx. 10 pptv) on a number of occasions during the campaign. Mahajan et al. (2009) modelled $\mathrm{I}_{2}$ concentrations measured by the LP-DOAS instrument during RHaMBLe, and also concluded that it was necessary to invoke substantial recycling of $\mathrm{I}_{2}$. Further chemical modelling was performed to support the present study, re-running the Mahajan et al. (2009) model for different $\mathrm{I}_{2}$ photolysis rates with and without $\mathrm{NO}_{\mathrm{x}}$ present. It was found that the decrease in $\mathrm{I}_{2}$ concentrations downstream of an emission source (using a baseline $\mathrm{NO}_{2}$ concentration of $2 \mathrm{ppbv}$ ) was well matched to the results of re-running the Mahajan et al. (2009) model with the $\mathrm{NO}_{\mathrm{x}}$ chemistry "turned off" but with an $\mathrm{I}_{2}$ photolysis rate reduced to only $10 \%$ of its usual value. Hence a very simplistic recycling scheme was introduced into the present model (which has no $\mathrm{NO}_{\mathrm{x}}$ chemistry) to mimic the effects of $\mathrm{I}_{2}$ recycling in a semi-polluted $\mathrm{NO}_{\mathrm{x}}$ environment by reducing the effective $\mathrm{I}_{2}$ photolysis frequencies, starting with a recycling parameter of $R=0.90$ (i.e. the $\mathrm{I}_{2}$ photolysis rate is reduced to $10 \%$ of its measured value, as suggested by the extra Mahajan et al. (2009) modelling).

Employing a recycling rate of $R=0.90$ produced modelled $I_{2}$ concentrations that were still generally below 5 pptv during daylight hours. Except for clean condition encountered on one day (25 September; $\left[\mathrm{NO}_{2}\right]$ less than $0.5 \mathrm{ppbv}$ ) when good quality BBCRDS data consistently showed $\mathrm{I}_{2}$ concentrations below $10 \mathrm{pptv}$, recycling rates of $R=0.95$ to 0.98 needed to be included in the model to bring the modelled $I_{2}$ into agreement with the observed $I_{2}$ amounts. It should be noted that more extensive $\mathrm{I}_{2}$ recycling (i.e. $R>0.90$ ) is expected when $\mathrm{NO}_{2}$ concentrations are above 2 ppbv (which was often the case during RHaMBLe), as a greater fraction of iodine will be converted into the temporary $\mathrm{IONO}_{2}$ reservoir to act as a potential downstream source of $\mathrm{I}_{2}$. The greater recycling efficiencies required in the present model do not necessarily mean $\mathrm{I}_{2}$ recycling chemistry is even more extensive than proposed in the original Mahajan et al. (2009) study; it may just be a consequence of the simplistic scheme our model has used to parameterise $\mathrm{I}_{2}$ recycling.

However, the semi-polluted $\mathrm{NO}_{\mathrm{x}}$ regime at Roscoff is, as noted by Mahajan et al. (2009), rather different from that for previous $\mathrm{I}_{2}$ measurements at cleaner background sites, most notably at the Mace Head Atmospheric Research Station (Galway, Ireland) where typical $\mathrm{NO}_{2}$ concentrations (Heard et al., 2006) are below the minimum $\mathrm{NO}_{2}$ levels observed during RHaMBLe and thus little recycling of $\mathrm{I}_{2}$ via $\mathrm{IONO}_{2}$ chemistry is expected. 
Analysis such as that produced in this paper is recommended to aid the interpretation of results from in situ measurements performed in complex environments containing spatially inhomogeneous and temporally varying emission fields. Ideally the framework presented in this paper would, in future, be coupled with a suitable chemistry scheme to model $\mathrm{I}_{2}$ observations with a full treatment of the $\mathrm{NO}_{\mathrm{x}}$ dependent recycling chemistry. An enhanced scheme could also then be used to model other observables in iodine's marine boundary layer chemistry, most importantly the IO radical and iodine-induced particle nucleation (von Glasow and Crutzen, 2007; McFiggans et al., 2010). The formation of IO from $\mathrm{I}_{2}$ (via $\mathrm{I}_{2}$ photolysis and reaction of the resulting $\mathrm{I}$ atoms with $\mathrm{O}_{3}$ ) happens rapidly on the timescale of $10 \mathrm{~s}$ during the day, whereas nucleation of particles from IO $\rightarrow$ $\mathrm{OIO} \rightarrow$ viable nuclei $\rightarrow$ detectible particles inevitably occurs over longer timescales. Thus these processes are likely to be affected differently by variable meteorology and spatially inhomogeneous emission fields, even for co-located $\mathrm{I}_{2}$, IO and particle measurements.

Total regional emissions for the $100 \mathrm{~km}^{2}$ zone around Roscoff have been modelled to be up to $1.7 \times 10^{19}$ molecules per second during the lowest tides. The dominant contribution to regional emissions is predicted to derive from $L$. hyperborea and to a lesser extent $L$. digitata from a scaling of laboratory-based studies of $\mathrm{I}_{2}$ emission rates from the different seaweed species and speciated maps of their habitats around Roscoff. Whereas the major contributor to the net regional emissions is L. hyperborea, this modelling has shown that the majority of the BBCRDS and LP-DOAS $\mathrm{I}_{2}$ signals derive from $L$. digitata and L. ochroleuca. Although the L. hyperborea seaweed beds are too far away from the SBR and LP-DOAS light path to (usually) be included in the footprints of air advected to the measurement locations, $L$. hyperborea and L. digitata emissions are almost certainly still the dominant source of newly nucleated aerosol particles since (i) these seaweed species are the strongest emitters (Ball et al., 2010) and (ii) particle nucleation is a non-linear process occurring in "hot spots" of locally elevated concentrations of iodine oxides (Burkholder et al., 2004). Thus spatial inhomogeneity in the emission field is likely to be even more influential on the kinetics of particle nucleation than for the $\mathrm{I}_{2}$ observations discussed in this work.

This study has illustrated the challenge of combining observational data from point and/or line sensors with emission maps to produce a metric representative of the net regional emissions, without extensive spatially-resolved dynamical and chemical modelling. These findings have been demonstrated for the marine coastal environment in this study, but are equally applicable in any other scenario in which emissions are spatially inhomogeneous and temporally variable (e.g. multiple emission sources in the urban environment). The value of long-path DOAS techniques that measure absorber amounts over an extended air mass already provide the ability to survey multiple emission sources within their line of sight. In the future, such advantages could be extended by deploying open-path DOAS systems that use scattered sunlight and can scan the direction of their field of view over the entire measurement region to build a map of absorber concentrations, provided that appropriate detection limits and the ability to isolate local emissions could be assured.

Acknowledgements. The authors would like to thank the staff at the Station Biologique de Roscoff for their significant assistance during the RHaMBLe project, and the Natural Environment Research Council for funding the RHaMBLe campaign. Deployment of the BBCRDS instrument to the RHaMBLe campaign was made possible through a grant from the Natural Environment Research Council NE/D00652X/1.

Edited by: E. Pelinovsky

\section{References}

Arzel, P.: Les laminaires sur les côtes bretonnes, évolution de l'exploitation et de la flottille de pêche, état actuel et perspectives, Edition de l'Ifremer, p. 139, 1998.

Bajjouk, T., Guillaumont, B., and Populus, J.: Application of airborne imaging spectrometry system data to intertidal seaweed classification and mapping, Hydrobiologia, 327, 463-471, 1996.

Ball, S. M. and Jones, R.: Broad-band cavity ring-down spectroscopy, Chem Rev., 103, 5239-5262, 2003.

Ball, S. M. and Jones, R.: Broadband cavity ring-down spectroscopy, in "Cavity ring-down spectroscopy: Techniques and applications", edited by: Berden, G. and Engeln, R., Blackwell Publishing Ltd, 2009.

Ball, S. M., Hollingsworth, A. M., Humbles, J., Leblanc, C., Potin, P., and McFiggans, G.: Spectroscopic studies of molecular iodine emitted into the gas phase by seaweed, Atmos. Chem. Phys., 10, 6237-6254, doi:10.5194/acp-10-6237-2010, 2010.

Bitter, M., Ball, S., Povey, I., and Jones, R.: A broadband cavity ringdown spectrometer for in-situ measurements of atmospheric trace gases, Atmos. Chem. Phys., 5, 3491-3532, doi:10.5194/acp-8-3491-2005, 2005.

Braud, J.-P.: Etude de quelques paramètres écologiques, biologiques et biochimiques chez une phéophycée des côtes bretonnes Laminaria ochroleuca, Revue des Travaux de l'Institut des Pêches Maritimes (ISTPM), 38, 1974.

Burkholder, J. B., Curtius, J., Ravishankara, A. R., and Lovejoy, E. R.: Laboratory studies of the homogeneous nucleation of iodine oxides, Atmos. Chem. Phys., 4, 19-34, doi:10.5194/ acp-4-19-2004, 2004.

Dixneuf, S., Ruth, A. A., Vaughan, S., Varma, R. M., and Orphal, J.: The time dependence of molecular iodine emission from Laminaria digitata, Atmos. Chem. Phys., 9, 823-829, doi: 10.5194/acp-9-823-2009, 2009.

Edwards, G. D. and Monks, P.: Performance of a single monochromator diode array spectroradiometer for the determination of actinic flux and atmospheric photolysis frequencies., J. Geophys. Res., 108, 8546, 2003.

Gévaert, F., Janquin, M.-A., and Davoult, D.: Biometrics in Laminaria digitata: a useful tool to assess biomass, carbon and nitrogen contents., J. Sea Res., 60, 215-219, 2008. 
Golléty, C., Migné, A., and D., D.: Benthic metabolism on a sheltered rocky shore: role of the canopy in the carbon budget., J. Phycol., 44, 1146-1153, 2008.

Heard, D. E., Read, K. A., Methven, J., Al-Haider, S., Bloss, W. J., Johnson, G. P., Pilling, M. J., Seakins, P. W., Smith, S. C., Sommariva, R., Stanton, J. C., Still, T. J., Ingham, T., Brooks, B., De Leeuw, G., Jackson, A. V., McQuaid, J. B., Morgan, R., Smith, M. H., Carpenter, L. J., Carslaw, N., Hamilton, J., Hopkins, J. R., Lee, J. D., Lewis, A. C., Purvis, R. M., Wevill, D. J., Brough, N., Green, T., Mills, G., Penkett, S. A., Plane, J. M. C., Saiz-Lopez, A., Worton, D., Monks, P. S., Fleming, Z., Rickard, A. R., Alfarra, M. R., Allan, J. D., Bower, K., Coe, H., Cubison, M., Flynn, M., McFiggans, G., Gallagher, M., Norton, E. G., O'Dowd, C. D., Shillito, J., Topping, D., Vaughan, G., Williams, P., Bitter, M., Ball, S. M., Jones, R. L., Povey, I. M., O'Doherty, S., Simmonds, P. G., Allen, A., Kinnersley, R. P., Beddows, D. C. S., Dall'Osto, M., Harrison, R. M., Donovan, R. J., Heal, M. R., Jennings, S. G., Noone, C., and Spain, G.: The North Atlantic Marine Boundary Layer Experiment(NAMBLEX). Overview of the campaign held at Mace Head, Ireland, in summer 2002, Atmospheric Chemistry and Physics, 6, 2241-2272, doi:10.5194/acp-6-2241-2006, 2006.

Lüning, K.: Seaweeds: Their environment, biogeography, and ecophysiology., Wiley, 1990.

Mahajan, A., Oetjen, H., Saiz-Lopez, A., Lee, J. D., McFiggans, G. B., and Plane, J. M. C.: Reactive iodine species in a semipolluted environment, Geophys. Res. Lett., 36, L16803, doi: 10.1029/2009GL038018, 2009.

Martin, F., Bacis, R., Churassy, S., and Vergès, J.: Laser-inducedfluorescence Fourier transform spectrometry of the $\mathrm{X}_{1} \Sigma_{g}^{+}$state of $\mathrm{I}_{2}$ : Extensive analysis of the $\mathrm{B}^{3} \Pi_{u}^{+} \rightarrow X^{1} \Sigma_{g}^{+}$fluorescence spectrum of ${ }^{127} I_{2}$, J. Molec. Spectrosc., 116, 71, 1986.

McFiggans, G., Coe, H., Burgess, R., Allan, J., Cubison, M., Alfarra, M. R., Saunders, R., Saiz-Lopez, A., Plane, J. M. C., Wevill, D., Carpenter, L., Rickard, A. R., and Monks, P. S.: Direct evidence for coastal iodine particles from Laminaria macroalgae - linkage to emissions of molecular iodine, Atmos. Chem. Phys., 4, 701-713, doi:10.5194/acp-4-701-2004, 2004.

McFiggans, G., Bale, C. S. E., Ball, S. M., Beames, J. M., Bloss, W. J., Carpenter, L. J., Dorsey, J., Dunk, R., Flynn, M. J., Furneaux, K. L., Gallagher, M. W., Heard, D. E., Hollingsworth, A. M., Hornsby, K., Ingham, T., Jones, C. E., Jones, R. L., Kramer, L. J., Langridge, J. M., Leblanc, C., LeCrane, J.-P., Lee, J. D., Leigh, R. J., Longley, I., Mahajan, A. S., Monks, P. S., Oetjen, H., Orr-Ewing, A. J., Plane, J. M. C., Potin, P., Shillings, A. J. L., Thomas, F., von Glasow, R., Wada, R., Whalley, L. K., and Whitehead, J. D.: Iodine-mediated coastal particle formation: an overview of the Reactive Halogens in the Marine Boundary Layer (RHaMBLe) Roscoff coastal study, Atmos. Chem. Phys., 10, 2975-2999, doi:10.5194/acp-10-2975-2010, 2010.
Plane, J. M. C. and Saiz-Lopez, A.: Analytical techniques for atmospheric measurement., Blackwell, 2006.

Platt, U.: Modern methods for the measurement of atmospheric trace gases, Phys. Chem. Chem. Phys., 1, 5409-5415, 1999.

Saiz-Lopez, A. and Plane, J. M. C.: Novel iodine chemistry in the marine boundary layer, Geophys. Res. Lett., 31, L04 112, doi: 10.1029/2003GL019215, 2004.

Saiz-Lopez, A., Saunders, R., Joseph, D. M., Ashworth, S. H., and Plane, J. M. C.: Absolute absorption cross-section and photolysis rate of $\mathrm{I}_{2}$, Atmos. Chem. Phys., 4, 1443-1450, doi:10.5194/acp4-1443-2004, 2004.

Saiz-Lopez, A., Plane, J. M. C., McFiggans, G., Williams, P. I., Ball, S. M., Bitter, M., Jones, R. L., Hongwei, C., and Hoffmann, T.: Modelling molecular iodine emissions in a coastal marine environment: the link to new particle formation., Atmos. Chem. Phys., 6, 883-895, doi:10.5194/acp-6-883-2006, 2006.

Schmid, H. P.: Source areas for scalars and scalar fluxes, Boundary Layer Meteorology, 67, 293-318, 1994.

Shillings, A.: Atmospheric applications of broadband cavity ringdown spectroscopy, PhD. Thesis, University of Cambridge, 2009.

Vandaele, A., Hermans, C., Simon, P., Van Roozendael, M., Guilmot, J., Carleer, M., and Colin, R.: Fourier transform measurement of $\mathrm{NO}_{2}$ absorption cross-sections in the visible range at room temperature, J. Atm. Chem., 25, 289-305, 1996.

von Glasow, R. and Crutzen, P.: Tropospheric halogen chemistry, in : Treatise on Geochemistry, edited by: Holland, H. D. and Turekian, K. K., Pergamon, Oxford, 167,doi:doi:10.1016/B0-08-043751-6/04141-4, http://www. sciencedirect.com/science/article/B782S-4CJV6M2-15\%/2/ 35ca9af61527f9815d05a526b4673865, 2007.

Western, C.: PGOPHER: a program for simulating rotational structure, available: University of Bristol, http://pgopher.chm.bris.ac. uk, Access: September 2009.

Zilitinkevich, S. S.: On the computation of the basic parameters of the interaction between the atmosphere and the ocean., Tellus, 21, 17-24, 1969. 